\title{
Problems of selecting filter partition in passenger car engine intake air filters
}

The aim of this study was to verify the criteria for selecting pleated filter partitions used in passenger car engine filters. The paper presents the problem of optimizing pleated air filters in the direction of minimizing pressure drop, which is the source of engine energy losses. Two criteria for selection of a paper filter partition for specific operating conditions of the filter and the engine are presented: criterion of permissible separation speed and criterion of permissible pressure drop. The actual filtration area of 44 paper pleated filter elements used in passenger cars and the air stream flowing through the filter were determined, which made it possible to calculate separation speed. In $62 \%$ of the analyzed filter inserts, the calculated separation speeds are within the speed range recommended by the constructors, $v_{F \max }=0.06-0.12 \mathrm{~m} / \mathrm{s}$. Exceeding permissible separation speed $v_{F \max }=0.12 \mathrm{~m} / \mathrm{s}$ was found mainly in supercharged engines. Negative effects of engine operation with an air filter with too small separation area are presented, in the form of increased pressure drop and energy loss of the engine as well as shorter car mileage to reach permissible pressure drop.

Key words: combustion engines, air filter, pleated filter cartridge, separation speed, pressure drop, dust absorption coefficient

\section{Introduction}

Together with the air, internal combustion engines of motor vehicles and working machines suck in significant amounts of pollutants from the environment, the basic component of which is mineral dust (road dust) carried from the ground by moving vehicles or by the wind. The basic components of road dust are: $\mathrm{SiO}_{2}$ silica and $\mathrm{Al}_{2} \mathrm{O}_{3}$ alumina, which share in dust reaches $95 \%$, and $\mathrm{Fe}_{2} \mathrm{O}_{3}$, $\mathrm{MgO}, \mathrm{CaO}$. Moreover, the dust contains: $\mathrm{K}_{2} \mathrm{O}, \mathrm{Na}_{2} \mathrm{O}, \mathrm{SO}_{3}$ $[4,48]$. Chemical composition of dust depends strictly on the composition and type of substrate, climatic factors (winds, rains, snow, frost, droughts, etc.), as well as on industrial dust, forest fire dust and volcanic ash [57].

Airborne dust is highly abrasive and is the most common cause of accelerated wear of two frictionally cooperating parts, such as the P-P-C (piston-piston rings-cylinder walls) connection in engines. On the ten-point Mohs scale, where 10 corresponds to the hardness of diamond, silica has a hardness of 7 , and corundum has 9 . Dust sucked in with the air gets over the piston, which is the reason why the upper part of the cylinder and piston and the upper piston rings wear the most. Abrasive wear of engine components is caused mainly by particles of $1-40 \mu \mathrm{m}$, with the most harmful particles in the range of $1-20 \mu \mathrm{m}[3,23,28]$.

Authors of thesis [28] report that about $30 \%$ of pollutants getting into the engine can escape, in principle, unchanged along with the exhaust gases from the cylinders to the exhaust system, thus increasing the emission of solid particles (PM) from the engine. Only $10-20 \%$ of the dust that enters into the engine with the air through the intake system settles on the cylinder liner wall. Together with the oil, this part of the dust forms a kind of abrasive paste which, in contact with the mating surfaces of the engine, for example P-PR-C, causes abrasive wear. The most dangerous for two cooperating engine components are dust particles whose diameter $\mathrm{dp}$ is equal to the oil film thickness $\mathrm{h}_{\text {min }}$ between this two surfaces at the moment. In typical combinations of internal combustion engine, oil thickness film depends on the conditions and parameters of the engine as well as the properties of the oil and, therefore, they assume different values in the range of $h_{\min }=0-10 \mu \mathrm{m}$ [55].
Moreover, the value of the minimum oil film thickness and the period of its occurrence in the engine cycle depends on sliding surfaces' shape asymmetry geometry [56]. Rest of the dust is evaporated or oxidized during the combustion of fuel in the cylinder (under high pressure and high temperature conditions).

In order to ensure adequate air purity at the inlet to traction engines and minimize wear of engine components, the intake system is equipped with an air filter, which, depending on the operating conditions of the vehicle, differs in principle, mode of operation, design, type of materials used for filtering partitions and efficiency. For this reason, passenger car engines operated at low dust concentrations are equipped with single-stage (partition) filters, where filter element is a cartridge made of filter paper or non-woven fabric. In order to increase the active surface of the insert, the material is pleated and then formed into a rectangular panel (Fig. 1). Truck engines, special vehicles (tanks, armored personnel carriers, infantry fighting vehicles) and working machines operated in conditions of high dust concentrations in the air are equipped with two-stage filters.

An additional task of the intake system is:

- supplying engine cylinders with air in appropriate amounts and with appropriate parameters in such a way as to ensure the correct course of the fuel combustion process in the engine cylinders [22, 25, 36, 50],

- noise suppression of combustion process in the engine [9],

- forcing the emergence of wave phenomena causing the so-called dynamic boost (resonant) at the desired engine operating ranges, thus increasing the filling and engine power [47].

Other elements of air supply system are: a flow meter, turbocharger, charge air cooler, air throttle on SI engines, intake manifold, inlet channels in the head and intake valves. Air flow meter located behind the air filter continuously registers flowing air mass and delivers this message in the form of a voltage signal to the microprocessor of the car's on-board computer.

Turbocharger (standard equipment in diesel engines) is to increase mass of the working medium supplied to the engine cylinders by increasing the pressure (also increases 
the temperature) of the air sucked into the system. The air cooler lowers the charge air temperature (its density increases), and thus the air mass flow to the engine cylinders increases. To register permissible resistance of air filters used in sectional and special trucks (exceptionally passenger cars), sensors are used, which are mounted on the outlet pipe from the air filter. Air supply system is linked to the operation of the crankcase ventilation system and the EGR (Exhaust Gas Recirculation) system.

Passenger car air filter is mounted in the engine compartment under the hood (Fig. 1). The shape of the filter is adapted to the limited space of this compartment. It also ensures easy access during service works, simple and easy assembly of the filter cartridge and other replaceable elements, tightness of its connections with the inlet manifold, minimum length of connecting pipes. The air is supplied to the filter by a special hose from the vehicle's surroundings, and the air intake is located in the front of it. a)

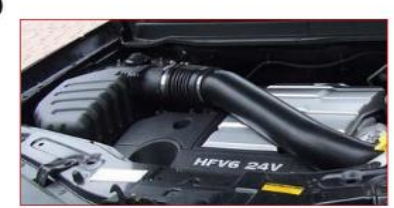

c)

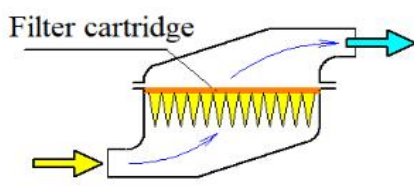

b)

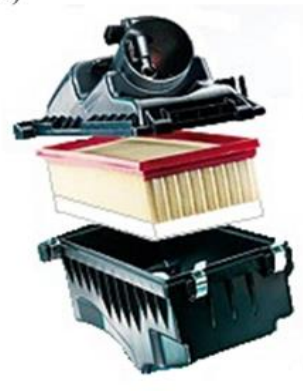

Fig. 1. Air filter in a modern passenger car: a) location of the air filter in the engine compartment, b) filter components, c) functional diagram [18]

A characteristic feature of partition filters is that during operation, as a result of the deposition and accumulation of dust particles in the filter bed, the filter pressure drop $\Delta \mathrm{p}_{\mathrm{f}}$, defined as a drop in static pressure behind the filter, systematically increases its value (Fig. 2).

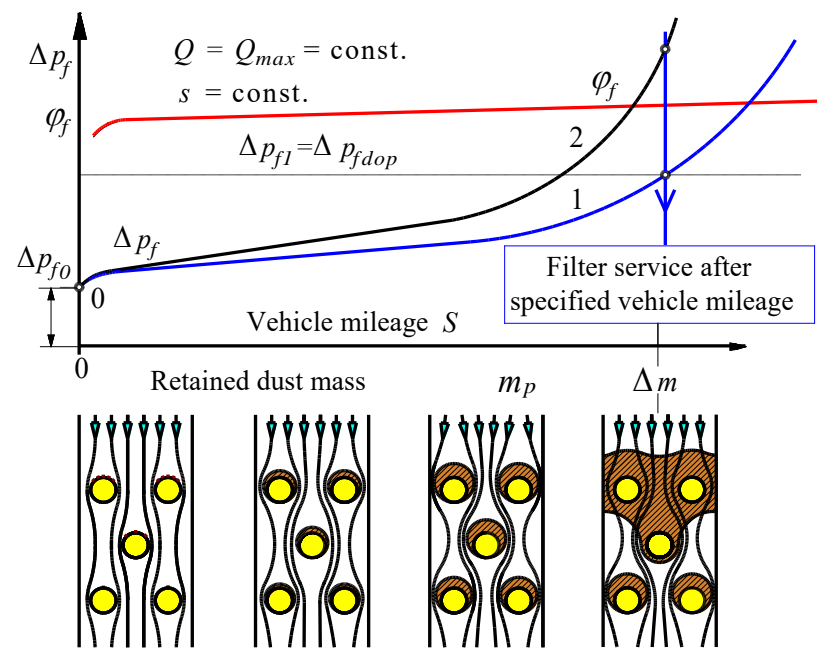

Fig. 2. Changes in separation efficiency and pressure drop of the partition air filter during operation: 1 - low air dustiness, 2 - large air dustiness

This causes additional engine energy losses. Intensity of increase in pressure drop depends on the conditions in which the vehicle is operated, mainly on the dust concentration in the air and the vehicle (engine) operating time. It is assumed that during operation, the air filter pressure drop should not exceed the permissible value $\Delta \mathrm{p}_{\text {fdop }}$, which is determined from the condition of a $3 \%$ decrease in engine power and is at the level of $2.5-4.0 \mathrm{kPa}$ - passenger car engines, 4-7 $\mathrm{kPa}$ - truck engines [3] and 9-12 $\mathrm{kPa}-$ special purpose vehicles [6]. From a technical point of view, service life of an air filter is commonly defined as the restriction level that causes the pressure on the passenger car filter to drop by about $2.5 \mathrm{kPa}$ above pressure drop of the new (clean) filter. For trucks and special vehicles, the $\Delta \mathrm{p}_{\text {fdop }}$ values are assumed to be approximately $6.25-7.5 \mathrm{kPa}$ above pressure drop of clean air filter [37]. Therefore, efforts are made to minimize pressure drop of clean air filters, which will reduce engine energy losses and extend the vehicle's mileage.

Dominant filter material used for operating fluids separation in vehicles, and in particular for intake air filtration of modern motor vehicle engines, are filter papers. They combine work of the way nets and nonwovens.

Filter papers are characterized by the following basic parameters: weight, paper thickness, average pore size, fiber diameter, dirt absorption, air permeability [5, 11].

As a result of continuous technological development of car engines, they are equipped with newer and newer systems and devices, for example an air conditioning system, a turbocharger, as a result of which the space available for the air filter is reduced. This results in a reduction in the filter area that can be used and an increase in separation speed and pressure drop, resulting in a loss of engine energy. For filter paper used in car air filters, maximum separation speed should not exceed the permissible value $(0.08$ $0.12 \mathrm{~m} / \mathrm{s}$ ) $[12,21]$. Exceeding this value is not only related to energy losses, it may also result in a decrease in separation efficiency due to bouncing and re-entrainment of particles [31].

Separation speed is defined as the average speed of the air stream flowing through the surface of the filter medium and it is determined from:

$$
\mathrm{v}_{\mathrm{Fmax}}=\frac{\mathrm{Q}_{\mathrm{Fmax}}}{\mathrm{A}_{\mathrm{C}} \cdot 3600}[\mathrm{~m} / \mathrm{s}]
$$

where: $\mathrm{Q}_{\mathrm{Fmax}}$ - maximum air stream flowing through the filter element, equal to the air demand by the engine $\mathrm{Q}_{\text {Silmax }}$ $\left[\mathrm{m}^{3} / \mathrm{h}\right]$ at the rotational speed of maximum power and $100 \%$ of the mixture throttle opening (engines with SI), $\mathrm{A}_{\mathrm{c}}-$ active filtering area of the cartridge $\left[\mathrm{m}^{2}\right]$.

Due to limited available space for mounting the filter in the space around car engine, filter paper or non-woven filter cartridges are made in a pleated form (Fig. 3), from which the filter cartridge can then be assembled in various ways. Most often they are panel inserts (Fig. 3d).

Filter cartridge is shaped so as to obtain the largest filter surface of the paper with the minimum volume of the cartridge and at the same time maintaining the condition of the maximum permissible air flow velocity through the filter bed - separation speed $v_{\text {Fmax }}$. This goal is achieved through the appropriate selection of the main design dimensions of the insert (Fig. 4) [16, 51]:

- pleat height $b_{p}$, 
- pleat width $\mathrm{a}_{\mathrm{w}}$,

- spacing between pleats $t_{p}$ (most often $t_{p}=2.2 \mathrm{~mm}$ ),

- insert length $\mathrm{L}_{\mathrm{p}}$.

a)

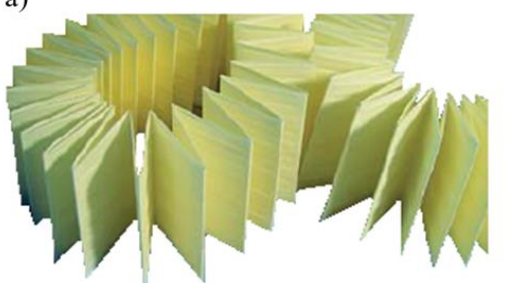

c)

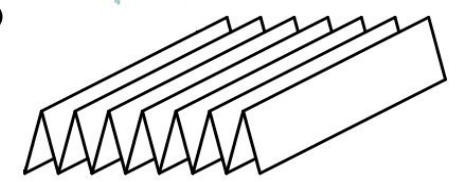

b)

d)
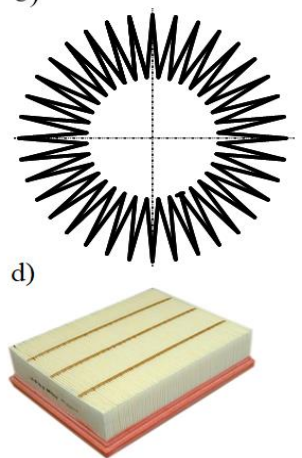

Fig. 3. Shaping the filter paper: a) paper after pleating, b) shaping into a multi-arm star, c) shaping into a panel, d) panel filter cartridge

At the same time, pleated paper filter elements should be constructed in such way that, with given design dimensions of the element and the required surface of the filter paper, they have maximum separation efficiency, minimum pressure drop and maximum durability.

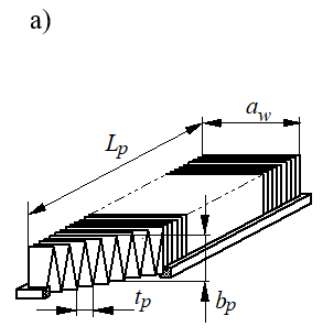

a)

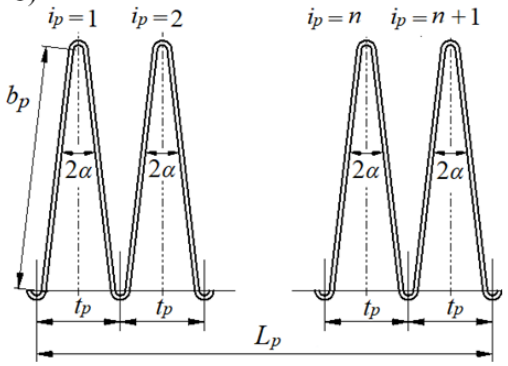

Fig. 4. Filter bed geometry: a) pleat geometry, b) $i_{p}$ - number of pleats, $L_{p}$ - insert length, $a_{w}-$ pleat width, $b_{p}-$ pleat side height, $t_{p}-$ pleat width, $\alpha$-half pleat inclination angle

Number and height of pleats and the spacing between the pleats (half-pleat angle) are the main parameters determining the surface of the filter paper, which is determined by:

$$
A_{c}=2 h_{p} \cdot a_{w} \cdot t_{p} \cdot i_{p}\left[m^{2}\right]
$$

Insert width $\mathrm{a}_{\mathrm{w}}$ and its length $\mathrm{L}_{\mathrm{p}}$ are limited by the size of the filter. A limited number of pleats can be placed at a given length $L_{p}$ and with a fixed spacing of the pleats $t_{p}$. Separation area can be increased by extending the side of the pleat $b_{p}$, which will lower separation speed value and pressure drop, but only to a certain value, because too high pleats are unstable, they warp and touch each other, causing separation surface loss. Separation area can be increased by increasing the number of pleats on a given section, which will reduce the flow velocity and lower the pressure drop, but also here there is a certain limit number of pleats, exceeding which will increase pressure drop. In the available literature, there is a significant number of works presenting the results of air filters optimization mainly in the direction of minimizing the pressure drop, which determines the engine energy losses. In the process of optimizing pleated engine air filters, separation efficiency is also taken into account.

Pleated air filters have been studied both numerically and experimentally by many researchers. It turned out that each pleated filter had the optimal number of pleats at which it showed a minimal pressure drop [1, 7, 10, 40, 41, 49, 53].

For example, the numerical studies performed by Fotovati et al. [20] showed that there is an optimal number of pleats for clean filters for which the pressure drop reaches a minimum, regardless of the orientation of the fibers in the surface. The triangular pleats result in a lower pressure drop. After allowing for particle deposition, the intensity of the pressure drop increase decreases as the number of pleats increases. Greater number of pleats results in a greater flow velocity inside the pleat channels, which results in a greater heterogeneity in the deposition of dust on the pleat. It has been observed that this effect is less visible when the pleats are triangular in shape. The authors [10], on the other hand, optimized the geometry of car filter pleats using the developed dimensionless model. The pressure drop on clean pleated filters was determined taking into account the geometric characteristics of the pleats (distance between pleats 1-3.5 mm, pleat heights $27,32,40,48 \mathrm{~mm}$ and separation speed in the range of $0.01-0.1 \mathrm{~m} / \mathrm{s}$. that for a given pleat height and constant air stream, there is such a width between the pleats for which the pressure drop reaches the lowest value. Park et al. [38] conducted research and various samples optimization of pleated filter elements by changing the angle between the pleat sides, the pleat length and the number of pleats. Highest separation efficiency was obtained when the dimensionless pleat coefficient defined as the quotient of pleat height (vertical distance from the top of the pleat to the base) and the pleat pitch (the distance between pleat apexes) was 1.48. Above this value, a systematic increase in the filter pressure drop was noted. Jinrui et al. [24] built a three-dimensional model of a pleated air filter on the basis of a real meltblown fiber, taking into account different filter parameters: pleat angle, layer thickness, diameter and number of fibers and curvature. It was found that at the stage of simulating pleated material separation characteristics, pressure drop increases nonlinearly with the increase of the deposited particles at the same gas inlet velocity. Maddineni et al. [31] numerically analyzed the phenomenon of particles permeating through a pleated panel-type air filter bed with a fleece height of $26 \mathrm{~mm}$, pleat spacing of $4.5 \mathrm{~mm}$ and an angle between the pleat sides of 2.5 degrees. A series of ISO 12103 A2 fine dust tests were carried out. An increase in particles penetration was found as a result of their rebound and retention at speeds above $0.5 \mathrm{~m} / \mathrm{s}$. Li et al. [27] investigated the influence of pleat geometry and their dust load on the pressure drop of pleated air filters. Six types of test chambers were designed with different pleat ratio with the same pleat side length. Analysis of experimental data showed that the effective separation area was mainly influenced by the pleat ratio, therefore it should be kept below 1.59. Chen et al. [8] carried out the simultaneous optimization of pressure drop 
and separation efficiency of pleated bed, adopting filter quality factor as the filter optimization and evaluation criterion, which combines separation efficiency and the pressure drop with:

$$
\mathrm{q}=\frac{-\ln \left(1-\varphi_{\mathrm{c}}\right)}{\Delta \mathrm{p}}[1 / \mathrm{kPa}]
$$

where: $\varphi_{\mathrm{c}}$ - cyclone separation efficiency, $\Delta \mathrm{p}-$ pressure drop for the nominal air stream $[\mathrm{kPa}]$.

They found that with the increase in the number of pleats, the value of the quality factor $q$ initially increased and then decreased. It was established that two parameters are decisive for this: number of pleats and their height. It has been shown during the research that the effectiveness of pleated filters depends not only on the particle size, but also on the number of pleats in the filter. Based on the filter quality factor, it has been found that the optimal number of pleats is always higher (about $0.3-0.5$ pleats per $10 \mathrm{~mm}$ ) than the one based on the pressure drop. The filter with the highest quality factor of the filter was obtained by the filter having a pleat number of 2.65 per $10 \mathrm{~mm}$ with a particle diameter of $122 \mathrm{~nm}$. Whereas Théron et al. [52] performed a numerical and experimental evaluation of the influence of pleat geometric features on the properties of fibrous filters in the deep separation phase of submicron aerosols. Wiegmann et al. [54] simulated a pleated air filter with various pleat shapes and different filter materials and assessed their impact on pressure drop. In [1], an experimentally and numerically tested pleated air filter with different parameters was carried out and its optimization aimed at improving the performance of a compression-ignition engine was carried out. A number of parameters were investigated including; pleat height, pleat spacing, pleat shape, filter medium thickness, air flow speed, engine speed, engine torque, fuel consumption and dust load. Three different shapes of pleats were considered: flat pleats, V-shaped pleats and sinusoidal pleats. Lowest pressure drop was obtained for a filter with a sinusoidal pleat shape, and the highest for a filter with a flat pleat shape. Reduced spacing of the pleats additionally resulted in a greater pressure drop of about $18 \%$, while an increased height of the pleats or the thickness of the pleat led to a reduction in pressure drop of about $43 \%$ and $10 \%$, respectively. Filter loaded with dust resulted in greater pressure drop and greater fuel consumption for the same engine torque and rotational speed. Engine with optimized filter achieved the lowest exhaust gas temperature of $218^{\circ} \mathrm{C}$, while the exhaust gas temperature with the standard filter reached $233^{\circ} \mathrm{C}$, but the highest exhaust temperature of $250^{\circ} \mathrm{C}$ was achieved by the engine with a dirty air filter. Mahesh [29] performed an analysis of fluid flow through the pleated air filter of a four-cylinder spark ignition engine by performing experimental and computational fluid dynamics (CFD) analysis to reduce pressure drop. It was found that a filter with triangular pleats achieves greater separation efficiency and lower pressure drop than a filter with rectangular pleats. Saleh and Tafreshi [43] carried out numerical studies in the field of pressure drop and separation efficiency of an air filter having a different number of rectangular and triangular pleats, both in depth and surface separation regimes with particles with a diameter of 1.5 and $10 \mu \mathrm{m}$ and in the range of separation speed $0.5-5 \mathrm{~m} / \mathrm{s}$. It has been shown that filters with rectangular pleats have the potential to provide better performance than their triangular counterparts under high dust loads. Rebai et al. [41] found that the optimal number of pleats resulting from the clean-state filter pressure drop tests was significantly lower than that based on dust mass retained in the filter. Fotovati et al. [19] investigated pleated bed geometry influence on dust deposition mechanism in pleats, as well as the pressure drop and separation efficiency related to it. They conducted numerical tests keeping the pleat height constant. Feng and Long [17] developed a macro-scale CFD simulation to investigate the optimal design of a pleated air filter under dust load conditions. It has been found that the optimal pleat density in a clean state can lead to a higher pressure drop and energy consumption during the dust separation process. It has been observed that the optimal dust deposition due to the pleat density depends on pleat height and is lower with higher height of the pleat. Maddineni et al. [30] numerically analyzed penetration phenomenon and particles penetration on a pleated, paneltype air filter with a pleat height of $26 \mathrm{~mm}$, pleat spacing of $4.5 \mathrm{~mm}$ and a pleat angle of 2.5 degrees. ISO $12103 \mathrm{~A} 2$ fine-grained dust was used, the concentration of which was $0.2 \mathrm{~g} / \mathrm{m}^{3}$ and different separation speeds in the range of $0.05-0.5 \mathrm{~m} / \mathrm{s}$. It was found that at low speed, i.e. $0.1 \mathrm{~m} / \mathrm{s}$, all particle sizes showed better separation. At high speed, i.e. $0.5 \mathrm{~m} / \mathrm{s}$, all particles showed minimal particle penetration. At velocities above $0.5 \mathrm{~m} / \mathrm{s}$, the amount of particles downstream of the filter material was found to increase, which meant very high particles penetration. For example, [32] presents the numerical methodology of forecasting the pressure drop in air filter with a pleated filter element. The pleat geometry and inlet velocity have been found to be the key parameters for the optimization of filter elements. The optimal pleats pitch was determined to obtain a minimum pressure drop and found to be largely dependent on pleat height. In [33 ] pleated air filter made of cellulose fibers has been analyzed in terms of optimal pleat geometry taking into account separation efficiency and pressure drop. The following pleat spacings were tested: $2.5,3.0,3.5,4.5$ and $5.5 \mathrm{~mm}$ and three levels of their height: 10,20 and $30 \mathrm{~mm}$. The optimal pleat geometry was found at a pleat height of $30 \mathrm{~mm}$ and with a spacing of $4.5 \mathrm{~mm}$. After soaking with oil, the pleated filter element with optimal pleat geometry showed a significant increase in separation efficiency at the expense of a slight increase in pressure drop. Compared to the contaminated pleated filter element, the oil-soaked filter exhibited higher separation efficiency at a higher air flow rate. The research [26] focused on examining the effect of pleated filters' properties and pleat geometry on pressure drop and separation efficiency, but also on air velocity distributions. It was found that both the geometry of the pleats and the pleat stabilization technique, which is commonly used in pleated filters, to maintain the shape of the pleat and the distance between the pleats, were influenced. Results suggest that in addition to the pleated filter geometry described by the shape of the pleat and its height, pleat density, geometric effects of blocking the pleats or their stabilization techniques should also be considered to estimate the flow effects in a more realistic way. The authors 
[35] assessed the optimal pleating geometry on the basis of separation quality coefficient $\mathrm{q}$, taking into account separation efficiency and the filter pressure drop. One flat filter and eight pleated filters $(4,6,8,10,15,21,25,30$ pleats) with pleat height of $29 \mathrm{~mm}$ and pleat width of $105 \mathrm{~mm}$ were prepared, and their separation efficiency and pressure drop were determined. It was found that the pressure drop of pleated filters with the number of folds above 21 , at the same air flow rate, increased with the number of pleats, which resulted from the increased separation speed due to the reduction of the effective separation area. On the other hand, pleated filter separation efficiency for particles (30, $50,100,200 \mathrm{~nm}$ ) increased with the increase in the number of pleats. Moreover, the highest filter quality factor $\mathrm{q}=5.8$ with a pleat height of $29 \mathrm{~mm}$ was found for the number of pleats of 21, which translated into the optimal pleat geometry.

From above considerations we found out that the problem of selecting pleated filter elements for an internal combustion engine is actual. Presented research shows that the effectiveness of a filter is determined by its geometry. The aim of this study was to verify the basic criterion for selecting a pleated air filter for an engine, which is separation speed $v_{F}$. Research was carried out by analyzing the geometry of pleated filter cartridges from several passenger car engines. Actual filter paper area of the panel inserts was determined as well as separation speed, which was compared with the permissible value of $v_{\text {Fmax }}$ applicable in the automotive industry.

It follows from above considerations that the problem of selecting pleated filter elements for internal combustion engine is actual. Presented research shows that the effectiveness of the filter (efficiency and pressure drop) is largely determined by the geometry of the pleated filter element and its surface. Characteristic parameter of the partition filter is permissible separation speed $v_{F m a x}$, which is the basic criterion for selecting a pleated filter element for a car engine air filter. Aim of this study was to verify this criterion and to analyze the factors determining the value of the distance traveled by the car until the filter obtains permissible pressure drop. In order to achieve the goal, the geometry of 44 pleated filter inserts for car engine filters was analyzed. Actual area of filter paper of the panel inserts was determined and separation speed was calculated for the rated engine operating conditions, and then compared with the permissible value of $v_{\text {Fmax }}$ applicable in the automotive industry. Theoretical relationship was used to analyze the factors determining the value of the distance traveled by the car until the filter obtained permissible pressure drop, which takes into account several experimentally determined factors.

\section{Model methodology and experimental research}

\subsection{Model research purpose and subject}

The aim of the research was to determine separation speed in dozens filter elements used in passenger car filters of various brands. Car engines differed mainly in the displacement and engine power as well as maximum power rotational speed-rated speed.

Research subject were panel-shaped, flat, cuboid-shaped filter elements made of pleated filter paper. These are typi- cal passenger car filter elements, differing in main external dimensions, pleats number, and thus filter paper surface (Fig. 5).

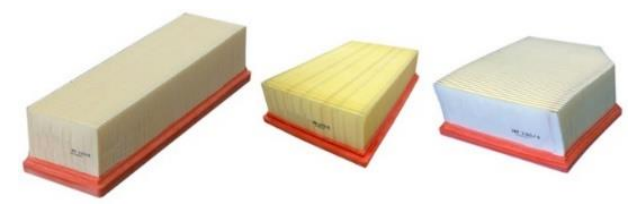

Fig. 5. Types of air filter elements: a) paper filter element, b) non-woven filter inserts

Basic criterion for selecting an active filtering surface $\mathrm{A}_{c}$ for a car air filter is the maximum separation speed $v_{\text {Fmax }}$, which for filter paper should be within the range [20, 44-46]:

- $0.06-0.12 \mathrm{~m} / \mathrm{s}$ - passenger car filter elements,

- 0.03-0.06 m/s - trucks and special vehicles filter inserts.

For a given maximum separation speed $v_{F \max }$, the active separation area is then determined from:

$$
A_{c}=\frac{Q_{v}\left(Q_{N}\right)}{3600 \cdot v_{F} \max }\left[m^{2}\right]
$$

This is the minimum required surface area of the filter paper. The use of a larger surface of the paper in the air filter automatically reduces separation speed, which will have a positive effect on the separation process (increase in efficiency and decrease in pressure drop) and extend the time to achieve the permissible pressure drop of the filter.

In order to obtain knowledge about the actual separation speeds in air filters used in car engines, it is necessary to know the active surface area of the filter material $A_{c}$ and the maximum value of the air stream flowing through this element $\mathrm{Q}_{\mathrm{Fmax}}$, which is equal to the air demand of the engine during its operation under rated conditions. For this purpose, measurements of the geometry of 44 pleated filter inserts from passenger car engine filters were performed, and then their actual filter paper surface was determined from relation 2 .

The maximum air demand of the $\mathrm{Q}_{\text {Silmax }}$ motor can be determined experimentally under laboratory conditions. It is the most reliable method, but also expensive and timeconsuming. For the comparative analyzes carried out in this study, the maximum air demand by the engine $\mathrm{Q}_{\text {Silmax }}=\mathrm{Q}_{\eta}$ was determined using the theoretical relationship [39]:

$$
\mathrm{Q}_{\mathrm{Silm} \max }=\mathrm{Q}_{\eta}=\frac{\mathrm{V}_{\mathrm{ss}} \cdot \mathrm{n}_{\mathrm{N}} \cdot \eta_{\mathrm{v}} \cdot 60}{1000 \cdot \kappa}\left[\mathrm{m}^{3} / \mathrm{h}\right]
$$

where: $V_{\mathrm{ss}}-$ engine cubic capacity $\left[\mathrm{dm}^{3}\right], \mathrm{n}_{\mathrm{N}}-$ maximum power rotation speed [rpm], $\kappa-$ stroke number factor (2- for four-stroke engines, 1 - for two-stroke engines), $\eta_{v}-$ filling factor, the value of which depends on the type of engine.

According to data from company Donaldson, when calculating the air demand of the engine, the filling factor $\eta_{v}$ of engine cylinders can be assumed as follows [15]:

- 0.85 - four-stroke diesel and SI naturally aspirated engines;

- 1.60 - four-stroke turbocharged diesel engines;

- 1.85 - four-stroke turbocharged diesel engines with an intake air cooler; 
Maximum air stream $\mathrm{Q}_{\text {Silmax }}$ flowing through the filter element can also be determined on the basis of the rated engine power using the following equations [15]:

$$
\mathrm{Q}_{\text {Silmax }}=\mathrm{Q}_{\mathrm{N}}=\mathrm{N}_{\mathrm{e}} \cdot \mathrm{Q}_{\mathrm{js}}\left[\mathrm{m}^{3} / \mathrm{min}\right]
$$

where: $\mathrm{N}_{\mathrm{e}}-$ maximum engine power $[\mathrm{HP}], \mathrm{Q}_{\mathrm{js}}-$ air flow $\left[\mathrm{m}^{3} / \mathrm{min}\right]$ per $1 \mathrm{HP}$ of engine power.

Value of the air stream $Q_{j s}$ per $1 \mathrm{HP}$ of engine power is recommended to be assumed as follows [15]:

- $0.057 \mathrm{~m}^{3} / \mathrm{min}$ for 4 -stroke naturally aspirated diesel engine,

- $0.065 \mathrm{~m}^{3} / \mathrm{min}$ for 4 -stroke turbocharged and cooled engine,

- $0.093 \mathrm{~m}^{3} / \mathrm{min}$ for 2 -stroke diesel engine with dust extraction by blower.

\subsection{Test results and calculations}

Figure 6 shows values of the nominal air stream flowing through 44 filter inserts from passenger car engine filters. Air stream $Q_{\eta}$ and $Q_{N}$ values were calculated using the filling degree criterion (relationship 2) and the power criterion (relationship 3).

Data for diesel and SI, naturally aspirated and turbocharged engines with and without charge air cooling were used for the calculations. Hence, the values of air flows obtained as a result of calculations for different engines with the same displacement $\mathrm{V}_{\mathrm{ss}}$ differ significantly. Moreover, values of nominal air demand by passenger car engines calculated with the filling criterion $Q_{\eta}$ reach values on average 5\% lower than those calculated with the power criterion $\mathrm{Q}_{\mathrm{N}}$.

For example, the nominal air demand of a four-stroke engine with SI $\left(\mathrm{V}_{\mathrm{ss}}=1.598 \mathrm{dm}^{3}-\right.$ No. 13 Fig. 6) of Opel Astra F Sedan 1.61 has values $Q_{\eta}=211.9 \mathrm{~m}^{3} / \mathrm{h}$ and $\mathrm{Q}_{\mathrm{N}}=$ $231.6 \mathrm{~m}^{3} / \mathrm{h}$, respectively. The difference between the two values is insignificant and is $\mathrm{R}_{\mathrm{Q}}=8.6 \%$. For a four-stroke engine with SI of the same displacement $\left(\mathrm{V}_{\mathrm{ss}}=1.598 \mathrm{dm}^{3}-\right.$ No. 12 Fig. 6) with a turbocharged Ford Fiesta III Hatchback 1.61 Turbo, the air demand is $Q_{\eta}=487.8 \mathrm{~m}^{3} / \mathrm{h}$ and $\mathrm{Q}_{\mathrm{N}}$ $=528.1 \mathrm{~m}^{3} / \mathrm{h}$. The difference between the two values $\mathrm{R}_{\mathrm{Q}}=$
7.8\%. For the Ford Fiesta III Hatchback 1.6 1 Turbo engine, the air flow rates $\mathrm{Q}_{\eta}$ and $\mathrm{Q}_{\mathrm{N}}$ are $50 \%$ higher than for the Opel Astra F Sedan 1.61 with the same $\mathrm{V}_{\mathrm{ss}}$ engine but without turbocharging.

Engine air demand $\mathrm{Q}_{\eta}$, determined according to the engine filling criterion, is calculated on the basis of the engine design parameters and the filling degree $\eta_{v}$. Value of $\eta_{v}$ is assumed depending on the engine type (diesel and SI): naturally aspirated, turbo charged or turbo charged with an intercooler. The recommendations say nothing about a drop in the fill level value in case of excessive wear of cylinders, which also affects power loss. Engine power is determined not only by the mass and type of fuel burned, but also by the process of preparing the combustible mixture, including air turbulence, injection, fuel fragmentation and evaporation, as well as the course of combustion of the mixture and fuel-air mixture. Air flow meter in the intake system is one of many sensors that provide signals on the basis of which the on-board computer selects the optimal operating conditions for the engine. In engines with the same cubic capacity and the same degree of cylinder filling, these processes may occur with different intensity, and thus the power obtained may have a different value. Therefore, the method of determining the air flow from the obtained engine power gives higher values than the method using the degree of filling. For analyzes in the further part of the thesis, the air stream was used, determined on the basis of the effective power of new engine, provided by the manufacturer.

Figure 7 shows, for comparison, the actual surface area $A_{R}$ of the filter inserts paper in passenger cars and the calculated area $A_{N}$ for the air stream $Q_{N}$ resulting from the maximum power and permissible separation speed $v_{\text {Fmax }}=$ $0.12 \mathrm{~m} / \mathrm{s}$. Figure 7 shows that in most cases the actual (active) filtering surface $A_{R}$ of the cartridges is greater than the calculated $A_{N}$ surface from the $Q_{N}$ stream and the permissible separation velocity condition $U_{F \max }=0.12 \mathrm{~m} / \mathrm{s}$. This indicates the correct selection of the filter surface and air filters for the vehicle.

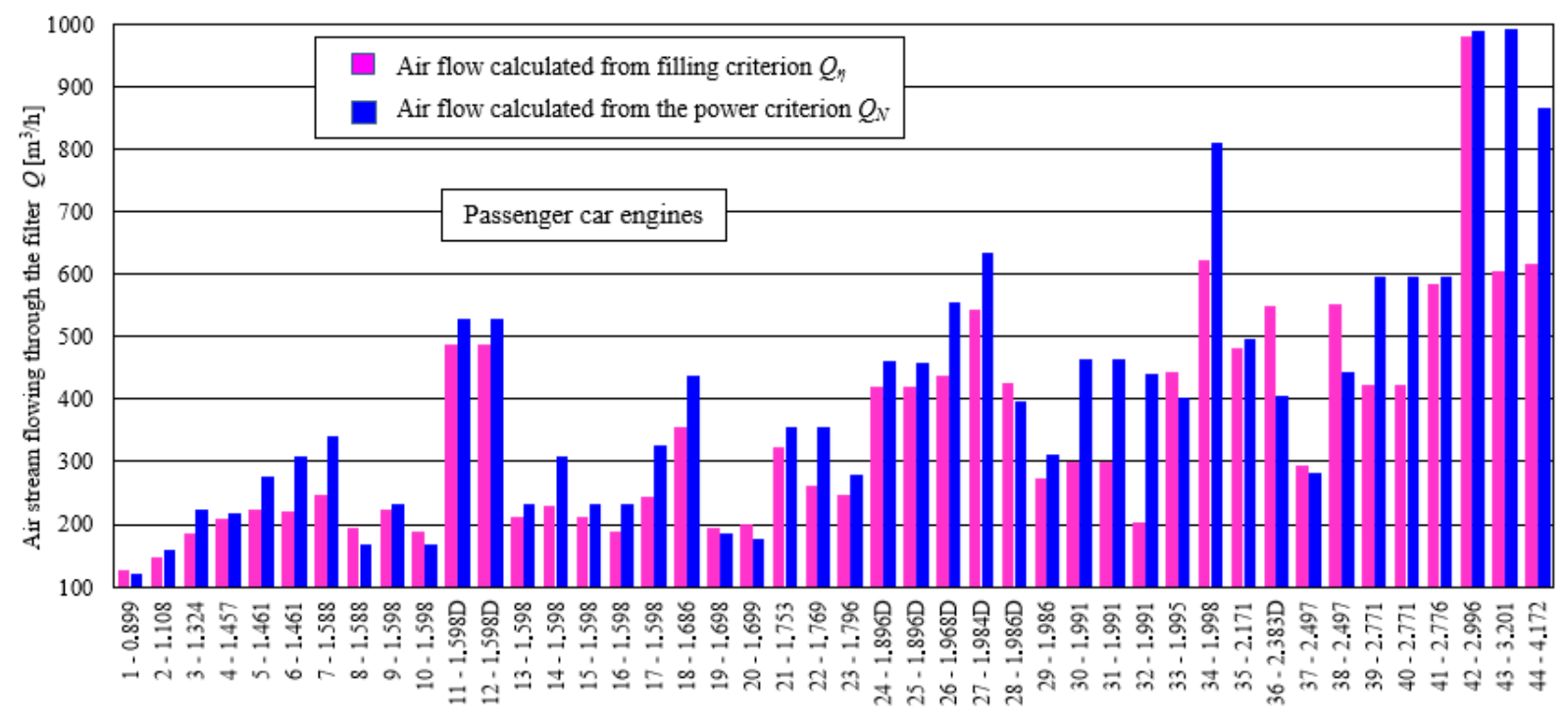

Number and engine cubic capacity $V_{s s}\left[\mathrm{dm}^{3}\right]$

Fig. 6. Nominal air stream $Q_{\eta}, Q_{N}$ values flowing through the filter elements in engine filters of different capacity 
Figure 7 shows, for comparison, the actual surface area $A_{R}$ of the filter inserts paper in passenger cars and the calculated area $A_{N}$ for the air stream $Q_{N}$ resulting from the maximum power and permissible separation speed $v_{\mathrm{Fmax}}=$ $0.12 \mathrm{~m} / \mathrm{s}$. Figure 7 shows that in most cases the actual (active) filtering surface $A_{R}$ of the cartridges is greater than the calculated $A_{N}$ surface from the $Q_{N}$ stream and the permissible separation velocity condition $U_{\mathrm{Fmax}}=0.12 \mathrm{~m} / \mathrm{s}$. This indicates the correct selection of the filter surface and air filters for the vehicle.

The air filter elements of engines No. 8, No. 16, No. 25 and No. 26 (Fig. 7) have actual separation surface $A_{R}$ significantly (2-3 times, and the engine air filter element No. 8 - four times) larger than the surface of $A_{N}$. Thus, the actual separation speed in these filter elements has a much lower value, respectively: $v_{F R}=0.028 \mathrm{~m} / \mathrm{s}, v_{F R}=0.041 \mathrm{~m} / \mathrm{s}$, $U_{\mathrm{FR}}=0.079 \mathrm{~m} / \mathrm{s}, U_{\mathrm{FR}}=0.075 \mathrm{~m} / \mathrm{s}$. Lower air flow velocity through the filter paper means lower pressure drop (lower engine energy losses) in the engine intake system and higher cylinder filling. Larger filter surface of the cartridge means its greater dust capacity, which will ensure a longer service interval of the car. In the case of the cars we discuss, there is a place nearby the engine that allows for placing an air filter with an element with such a large filter surface. On the other hand, in the case of engine filters No. 11, No. 12, No. 34, No. 42 and No. 43 (Fig. 7), the actual separation area $A_{R}$ is much smaller than the $A_{N}$ area resulting from the condition of the permissible separation speed $v_{\text {Fmax }}=0.12 \mathrm{~m} / \mathrm{s}$. Engines mentioned are supercharged engines which have significantly more power than similar naturally aspirated engines with the same cubic capacity. In the case of the filters mentioned, the designer did not take care of the proper selection of engine filter. This will result in increased pressure drop in the engine intake system and additional energy losses, especially in case of loading filter bed with dust.

Figure 8 shows values of separation speed $v_{\mathrm{N}}$ calculated on the basis of the power criterion and the actual (active) separation surface $A_{R}$ in passenger car filter inserts.

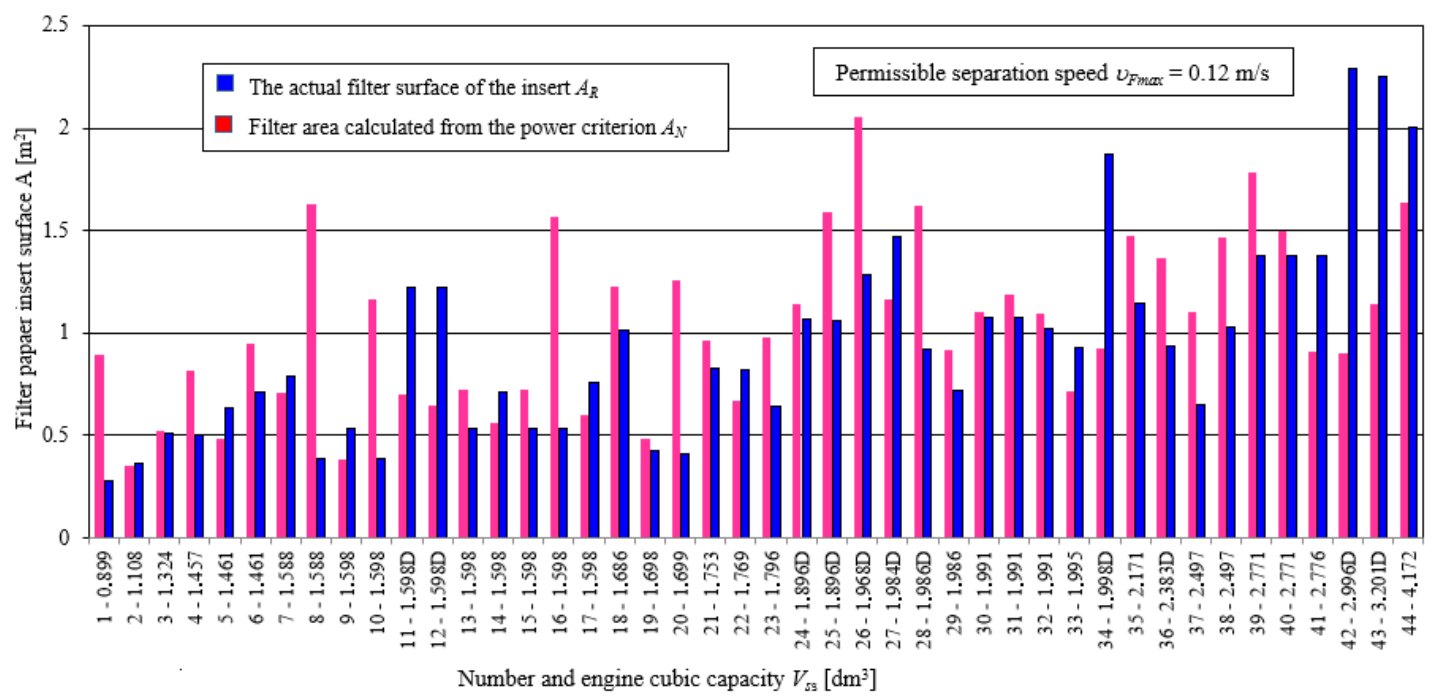

Fig. 7. Comparison of the paper surface used in passenger car engine filter inserts: the actual $A_{\mathrm{rz}}$ and the calculated $\mathrm{A}_{\mathrm{N}}$ for the separation speed $v_{\text {Fmax }}=0.12 \mathrm{~m} / \mathrm{s}$

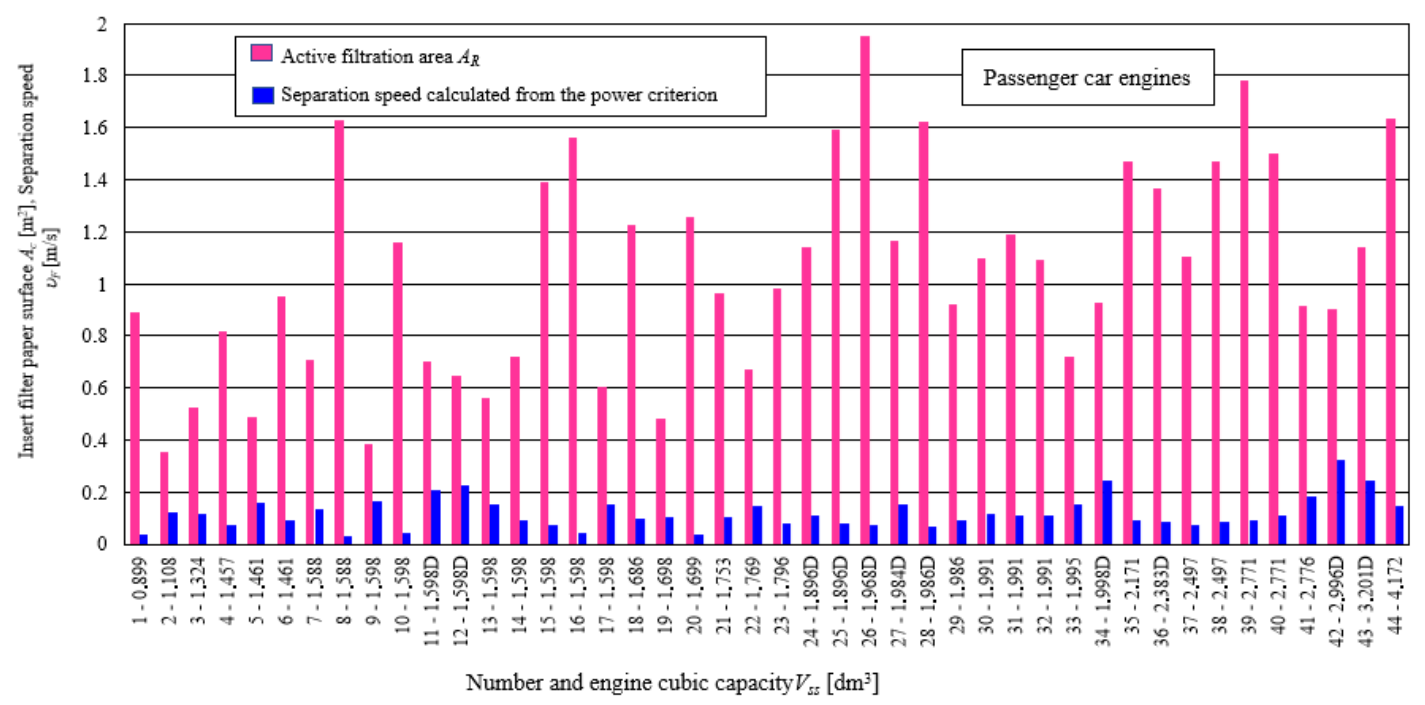

Fig. 8. Separation speed $v_{N}$ calculated on the basis of power criterion and active filtering surface $A_{R}$ in passenger car filter inserts 
In most cases (62\%) of analyzed filter inserts, the calculated separation speeds are within the range of $v_{\mathrm{Fmax}}=$ $0.06-0.12 \mathrm{~m} / \mathrm{s}$ recommended by the designers. The highest separation speed $v_{\mathrm{F}}=0.324 \mathrm{~m} / \mathrm{s}$ is characteristic for the BMW Z4 E85 3.0 SI passenger car insert (No. 42). It is a sport car with a power of $194 \mathrm{~kW}$, a cubic capacity $\mathrm{V}_{\mathrm{ss}}=$ $2.996 \mathrm{dm}^{3}$ and an active filter area $\mathrm{A}_{\mathrm{c}}=0.901 \mathrm{~m}^{2}$. In order that separation speed for this element did to exceed the permissible value $v_{\text {Fmax }}=0.12 \mathrm{~m} / \mathrm{s}$, the active separation area should be increased to $A_{c}=0.901 \mathrm{~m}^{2}$, i.e. almost three times. The actual filter surface used is likely to depend on the space available in the engine compartment to accommodate the air filter with the appropriate paper surface value.

Permissible speed value $\left(v_{\text {Fmax }}=0.12 \mathrm{~m} / \mathrm{s}\right)$ was also exceeded in the Opel Calibra I 2.0i Turbo $4 \times 4$ passenger car filter (No. 34). It is a vehicle with lower power $(150 \mathrm{~kW})$ and a smaller engine cubic capacity $\left(\mathrm{V}_{\mathrm{ss}}=1.998 \mathrm{dm}^{3}\right)$ compared to the engine from previous vehicle, but the active separation area is only $\mathrm{A}_{\mathrm{c}}=0.928 \mathrm{~m}^{2}$, which results in separation speed of $v_{F}=0.243 \mathrm{~m} / \mathrm{s}$. Similar significant excess of permissible speed value occurs in air filters in supercharged engines No. 11, 12 (Fig. 8).

On the other hand, air filter from Audi A4 B7 Sedan 2.0 TDI passenger car (No. 26), despite significant power (103 $\mathrm{kW})$ and cubic capacity $\left(\mathrm{V}_{\mathrm{ss}}=1.968 \mathrm{dm}^{3}\right)$ similar to the engine of the previous vehicle, reaches separation speed of $U_{\mathrm{F}}=0.0753 \mathrm{~m} / \mathrm{s}$, within the required range $v_{\mathrm{Fmax}}=0.06$ $0.12 \mathrm{~m} / \mathrm{s}$, which results from significant filter paper surface area $\left(A_{c}=1.95 \mathrm{~m}^{2}\right)$ used in this filter. Probably in the case of this car, nearby the engine, there is a place for placing an air filter with an element with such a large filter surface. A similar situation occurs in the case of Fiat Seicento 0.8 (No. 1), Volkswagen Golf II 1.6 (No. 8), Opel Kadett D (No. 10), Seat Cordoba II 1.6 (No. 16) and Opel Kadett E Estate (No. 20), where separation velocities are significantly lower than $0.06 \mathrm{~m} / \mathrm{s}$. Engines of the above-mentioned cars have much lower power, which is in the range of
28.68-55.15 kW, than the engines from previous vehicles. It follows that an important factor determining the surface of the filter paper is the free space around the engine where it is possible to locate the air filter. Analysis shows that there is more of this free space in cars where the power unit is low-power engine.

Figure 9 shows values of separation speed in naturally aspirated engines with the same cubic capacity $\mathrm{V}_{\mathrm{ss}}=1.598$ $\mathrm{dm}^{3}$ in following cars: Volkswagen Jetta II (No. 9), Opel Corsa A (No. 13), Opel Astra F (No. 14), Opel Zafira B (No. 15) and Seat Cordoba II (No. 16). Car engines 9, 14 and 16 also have the same power $55.15 \mathrm{~kW}$, and thus the value of the stream, but due to the different value of the active surface of filter paper of the cartridge, the separation speeds reach various values, respectively $v_{F}=0.167,0.89$, $0.041 \mathrm{~m} / \mathrm{s}$.

Similarly, in the case of car engines No. 13 and 15. Despite the same cubic capacity $\mathrm{V}_{\mathrm{ss}}=1.598 \mathrm{dm}^{3}$ and slight differences in power, the separation speeds differ twice (Fig. 9). In the air filters in engines 9 and 13, the separation speeds significantly exceed the permissible value $v_{\text {Fmax }}=$ $0.12 \mathrm{~m} / \mathrm{s}$. This is a clear proof that the rules for selecting air filters are not followed. For the vehicle user, these are energy losses in the form of power loss, increased fuel consumption and reduced vehicle acceleration.

\subsection{Factors determining distance value traveled \\ by a car}

Selection of active separation surface $A_{c}$ according to the criterion of maximum separation speed $v_{\mathrm{Fmax}}$ is not a sufficient condition. It is necessary to check whether the $A_{c}$ surface selected in this way will ensure the required operating time of the air filter corresponding to the assumed vehicle mileage until the service is performed - filter insert replacement. It is assumed that this is the time when the filter reaches the permissible resistance $\Delta \mathrm{p}_{\text {fdop }}$, which results from the assumed $3 \%$ decrease in engine power.

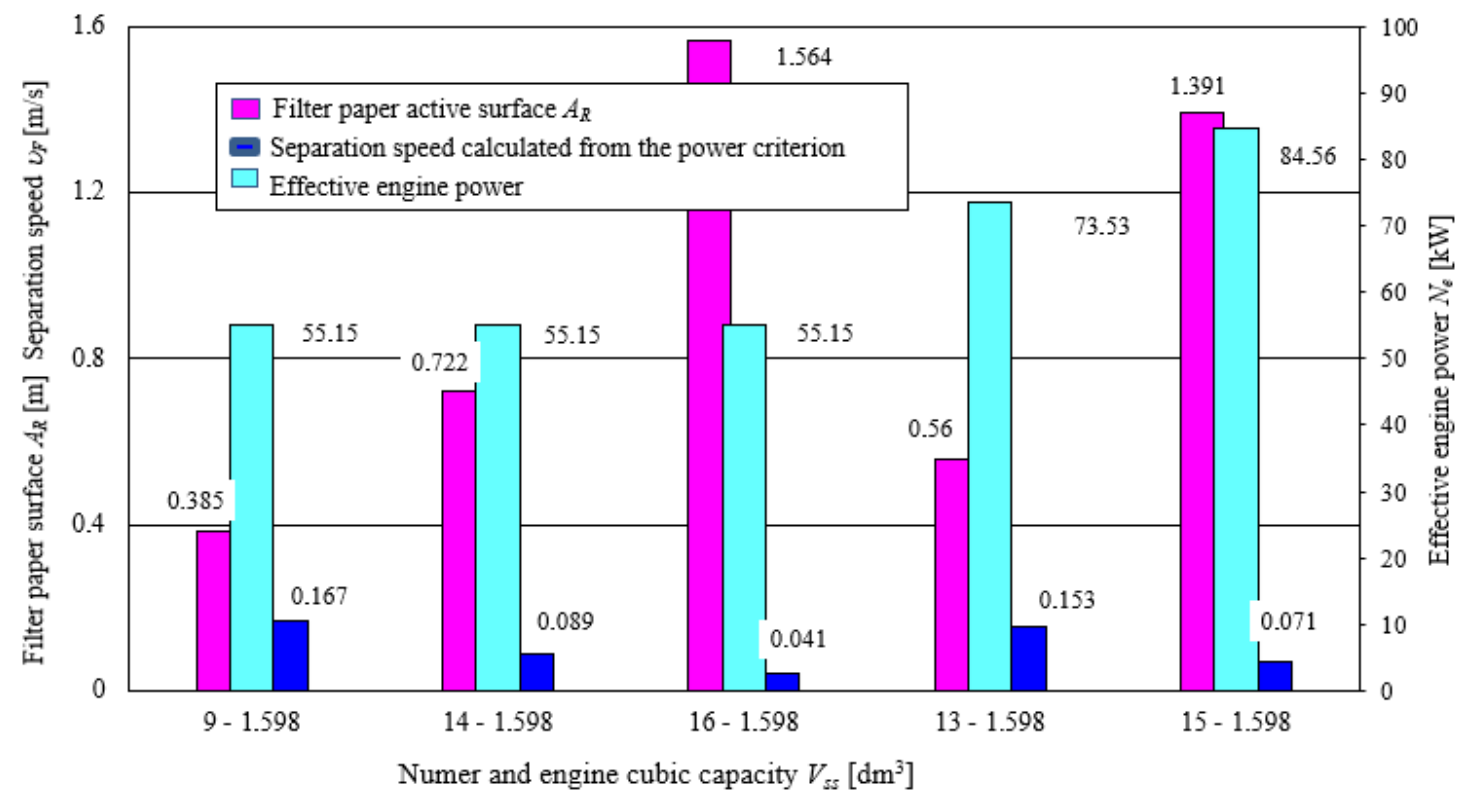

Fig. 9. Separation speed $v_{N}$ calculated from the power criterion and the actual separation area $A_{R}$ for passenger cars with cubic capacity $V_{s s}=1.598 \mathrm{dm}^{3}$ 
The distance traveled by the car until the filter reaches the assumed value of permissible resistance $\Delta \mathrm{p}_{\mathrm{fdop}}$ is determined by:

$$
\mathrm{S}_{\mathrm{p}}=v_{\mathrm{p}} \tau_{\mathrm{p}}[\mathrm{km}]
$$

where: $v_{p}-$ average vehicle speed $[\mathrm{km} / \mathrm{h}], \tau_{\mathrm{p}}-$ air filter operation time until the filter reaches the accepted value of permissible resistance $\Delta \mathrm{p}_{\text {fdop }}$.

Operation time $\tau_{\mathrm{pI}}$ of a single-stage air filter can be determined from [7]:

$$
\tau_{\text {cpI }}=\frac{A_{c} \cdot k_{m} \cdot k_{c}}{Q_{\text {sil max }} \cdot s \cdot \varphi_{p}}[\mathrm{~h}]
$$

where: $\mathrm{k}_{\mathrm{m}}$ - filter paper absorbency coefficient $\left[\mathrm{g} / \mathrm{m}^{2}\right]$, $\mathrm{k}_{\mathrm{c}}$ - coefficient taking into account the difference between the parameters of test pollutants and actual pollutants, $\mathrm{Q}_{\text {Silmax }}$ - nominal air demand by the engine $\left[\mathrm{m}^{3} / \mathrm{h}\right]$, $\mathrm{s}-$ average dust concentration in the air sucked in by the filter $\left[\mathrm{g} / \mathrm{m}^{3}\right], \varphi_{P}-$ filter element efficiency.

After taking into account the above dependence, the distance traveled by the car until the one-stage filter reaches the permissible resistance $\Delta \mathrm{p}_{\text {fdop }}$ is determined by:

$$
\mathrm{S}_{\mathrm{p}}=\mathrm{V}_{\mathrm{p}} \frac{\mathrm{A}_{\mathrm{c}} \cdot \mathrm{k}_{\mathrm{m}} \cdot \mathrm{k}_{\mathrm{c}}}{\mathrm{Q}_{\mathrm{sil} \mathrm{max}} \cdot \mathrm{s} \cdot \varphi_{\mathrm{p}}}[\mathrm{km}]
$$

Vehicle mileage calculation from the above dependence requires a lot of experimental data that characterizes a specific filter material under specific operating conditions, the most important of which are: absorption coefficient $\mathrm{k}_{\mathrm{m}}$, material separation efficiency $\varphi_{\mathrm{P}}$, correction factor $\mathrm{k}_{\mathrm{c}}$, dust concentration s, chemical and duct particle size composition, air flow speed (air stream).

Factor $\mathrm{k}_{\mathrm{c}}$ takes into account mainly the influence of soot on the durability of the paper element, and it is determined by the ratio of filter operation time in real conditions to the filter operation time with test dust [34]. The significance of this coefficient, which assumes the value of $\mathrm{k}_{\mathrm{c}}<1$ (the higher the soot content, the lower the $\mathrm{k}_{\mathrm{c}}$ coefficient value, and the filter's working time is shorter), is large in the case of air filters with a paper element, which are equipped with vehicles operated in urban conditions, where soot is the predominant component of the engine intake air pollutants. In the case of vehicle engines operated in off-road conditions, the basic pollutant component is mineral dust, so taking into account the $\mathrm{k}_{\mathrm{c}}$ coefficient when determining the operating time of a two-stage filter can be omitted, because the test dust is similar to mineral dust in both chemical and particle size composition. Therefore, it should not have a significant impact on the results of calculations, which are estimates.

According to the authors $[14,20]$, the $\mathrm{k}_{\mathrm{m}}$ factor presented in the above equations is defined as: the quotient of the total dust mass $m_{\mathrm{PF}}$ retained and evenly distributed over the surface of the filter material until the permissible resistance value $\Delta \mathrm{p}_{\text {fdop }}$ and the active surface of the filter paper $\mathrm{A}_{\mathrm{c}}$ is reached:

$$
\mathrm{k}_{\mathrm{m}}=\frac{\mathrm{m}_{\mathrm{PF}}}{\mathrm{A}_{\mathrm{c}}}\left[\mathrm{g} / \mathrm{m}^{2}\right]
$$

Values of dust absorption coefficient $\mathrm{k}_{\mathrm{m}}$ for conventional filter materials based on cellulose and standard dusts, the grain size of which usually does not exceed $80-100 \mu \mathrm{m}$ (dust with such grain size goes directly to the filter element of a single-stage filter) were determined by the authors based on experimental studies [12, 28, 32] and assume maximum values in the range of $\mathrm{k}_{\mathrm{m}}=190-220 \mathrm{~g} / \mathrm{m}^{2}$.

Modern filtering materials for engine intake air separation are also made of other materials, e.g. polyester, cellulose with an additional layer of polyester or nanofibers, cellulose with a layer of polyester and nanofibers. These materials are characterized by much greater efficiency and accuracy, but also by lower values of the absorption coefficient $\mathrm{k}_{\mathrm{m}}$. According to the research of the authors of the work $[12,13]$, filter materials with a pressure drop of $\Delta p=$ $3 \mathrm{kPa}$ obtained the following absorption coefficients: polyester $\mathrm{k}_{\mathrm{m}}=135 \mathrm{~g} / \mathrm{m}^{2}$, cellulose with an additional layer of polyester $k_{m}=120 \mathrm{~g} / \mathrm{m}^{2}$, cellulose with a layer of polyester and nanofibers $\mathrm{k}_{\mathrm{m}}=102 \mathrm{~g} / \mathrm{m}^{2}$.

According to the authors [28] who tested the two-layer filter medium, the absorption coefficient reached the value of $\mathrm{k}_{\mathrm{m}}=84 \mathrm{~g} / \mathrm{m}^{2}$ with a pressure drop of $2 \mathrm{kPa}$, when the microfiber layer was placed as an inlet. On the other hand, when there was a sub-microfiber layer at the inlet, the dust holding capacity was $95 \mathrm{~g} / \mathrm{m}^{2}$, so it was $13 \%$ higher.

For filtering nonwovens used as filter elements for passenger car engines, the dust absorption coefficient $\mathrm{k}_{\mathrm{m}}$ assumes much higher values $\left(\mathrm{k}_{\mathrm{m}}=350-500 \mathrm{~g} / \mathrm{m}^{2}\right)$ than the filter paper, which may result from the greater thickness (2-5 mm) of the filter bed. For example, in [42] it is stated that the value of the absorbency coefficient of noncalendered nonwoven fabric with a thickness of $3.2 \mathrm{~mm}$, determined at pressure drop of $0.3 \mathrm{kPa}$, is $\mathrm{k}_{\mathrm{m}}=(54.5-89.3)$ $\mathrm{g} / \mathrm{m}^{2}$. The same non-woven calendered fabric has the absorption coefficient $\mathrm{k}_{\mathrm{m}}=(85.5-112.3) \mathrm{g} / \mathrm{m}^{2}$, and therefore it is much higher. The authors [11] state that the dust absorption coefficient of filtering nonwovens with a gradient structure has the value of $\mathrm{k}_{\mathrm{m}}=(900-1100) \mathrm{g} / \mathrm{m}^{2}$. However, the value of the pressure drop at which the $k_{m}$ value was determined was not given. According to [58], the dust absorption coefficients of nonwovens fabrics exceed the value of $(400-480) \mathrm{g} / \mathrm{m}^{2}$.

Modern filtering materials for filtering engine intake air are also made of other materials, e.g. polyester, cellulose with an additional layer of polyester or nanofibers, cellulose with a layer of polyester and nanofibers.

\subsection{Dust absorption coefficient experimental studies Research purpose and subject}

The aim of the research was to determine filter cartridges dust absorption coefficient $k_{m}$ made of various filter materials (cellulose, polyester, cellulose and polyester, cellulose and polyester with a nanofiber layer by determining the following separation characteristics:

- separation accuracy $\mathrm{d}_{\mathrm{zmax}}=\mathrm{f}\left(\mathrm{k}_{\mathrm{m}}\right)$,

- separation efficiency $\varphi_{\mathrm{w}}=\mathrm{f}\left(\mathrm{k}_{\mathrm{m}}\right)$,

- pressure drop $\Delta \mathrm{p}_{\mathrm{w}}=\mathrm{f}\left(\mathrm{k}_{\mathrm{m}}\right)$.

and flow (aerodynamic) characteristics $\Delta \mathrm{p}_{\mathrm{w}}=\mathrm{f}\left(\mathrm{Q}_{\mathrm{w}}\right)$, where: $\mathrm{Q}_{\mathrm{w}}$ - air stream flowing through filter element.

Research subject were filter inserts (Fig. 10) of the same type, with the same dimensions, same filtration area $\mathrm{A}_{\mathrm{w}}=0.1534 \mathrm{~m}^{2}$, but with different filter material. To facili- 
tate test results analysis, filter materials (cartridges) have been designated A, B, C, and D.

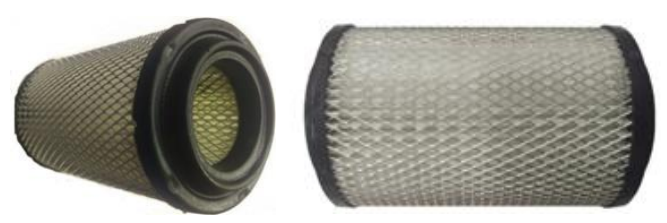

Fig. 10. Filter cartridge

Characteristic parameters and values of the selected filter materials are summarized in Table 1. A large variation in the parameter values can be seen. Filter material D (cellulose + polyester + nanofibers) is characterized by five times less air permeability than material $\mathrm{A}$ and two times smaller than materials $\mathrm{A}$ and $\mathrm{B}$ in thickness. There is a nanofiber layer on the inlet side of the filter material $\mathrm{D}$.

Table 1. Tested filtration materials parameters according to the manufacturer's data [12]

\begin{tabular}{|c|c|c|c|c|c|}
\hline No. & $\begin{array}{c}\text { Filtration } \\
\text { material }\end{array}$ & $\begin{array}{c}\text { Permeability } \\
\mathrm{q}_{\mathrm{p}}\left[\mathrm{dm}^{3} / \mathrm{m}^{2} / \mathrm{s}\right]\end{array}$ & $\begin{array}{c}\text { Grammage } \\
\mathrm{g}_{\mathrm{m}}\left[\mathrm{g} / \mathrm{m}^{2}\right]\end{array}$ & $\begin{array}{c}\text { Thickness } \\
\mathrm{g}_{\mathrm{z}}[\mu \mathrm{m}]\end{array}$ & $\begin{array}{c}\text { Max. pore } \\
\text { size } \mathrm{d}_{\mathrm{p}}[\mu \mathrm{m}]\end{array}$ \\
\hline $\mathrm{A}$ & Cellulose & 838 & 121 & 610 & 79 \\
\hline B & Polyester & 150 & 180 & 550 & - \\
\hline C & $\begin{array}{c}\text { Cellulose + } \\
\text { polyester }\end{array}$ & 150 & 130 & 350 & 58 \\
\hline D & $\begin{array}{c}\text { Cellulose + } \\
\text { polyester + } \\
\text { nanofibers }\end{array}$ & 185 & 120 & 300 & 48 \\
\hline
\end{tabular}

\section{Research methodology and conditions}

Tests were carried out on the stand (Fig. 11), which was equipped with Pamas - 2132 particle counter. counter records dust grains number and size in the air stream $\mathrm{Q}_{\mathrm{w}}$ after the tested filter cartridge in the range of $0.7-100 \mu \mathrm{m}$ in $\mathrm{i}=$ 32 measuring intervals, limited by diameters $\left(\mathrm{d}_{\text {zimin }} \div \mathrm{d}_{\text {zimax }}\right)$.

PTC-D test dust, which in Poland is a substitute for the $\mathrm{AC}$ fine test dust, the chemical and fractional composition of which is presented [39], is dosed into the housing, where the tested cylindrical filter cartridge is located. Dust grains mass fraction with a size of $0-5 \mu \mathrm{m}$ in total dust mass is almost $40 \%$. Due to their very small size, these dust grains are difficult to retain by porous filter materials. More than $67 \%$ of these grains are $\mathrm{SiO}_{2}$ grains, a mineral characterized by high hardness ( 7 on the 10-degree Mohs scale), thus causing accelerated engine components wear.

At the appropriate distance behind the tested filter, the tip of the measuring probe is placed centrally along the axis of the conductor, which is used to suck air into the particle counter sensor. Measuring cable ends with a special filter that prevents dust from getting into the rotameter.

Filter inserts flow characteristics $\Delta \mathrm{p}_{\mathrm{w}}=\mathrm{f}\left(\mathrm{Q}_{\mathrm{w}}\right)$ before the tests were determined for 8 measuring points in air stream range $\mathrm{Q}_{\mathrm{w}}=\mathrm{Q}_{\mathrm{wmin}}-\mathrm{Q}_{\mathrm{wmax}}$. Maximum stream value $\mathrm{Q}_{\mathrm{wmax}}=$ $56 \mathrm{~m}^{3} / \mathrm{h}$ was determined for maximum filtration speed $v_{\mathrm{Fw}}=$ $0.1 \mathrm{~m} / \mathrm{s}$. For passenger car filters, maximum paper filtration speed value is within the range $v_{\mathrm{Fw}}=0.07-0.12 \mathrm{~m} / \mathrm{s}[18,20$, 53-56].

Filter cartridge flow characteristics test results $\Delta \mathrm{p}_{\mathrm{w}}=$ $f\left(Q_{w}\right)$ (before testing with dust) are shown on Fig. 12. As the air stream increases, flow resistance increases parabolic $\Delta \mathrm{p}_{\mathrm{w}}=\mathrm{f}\left(\mathrm{k}_{\mathrm{m}}\right)$, which is consistent with the literature .

Highest flow resistance values in the entire range of the test air stream $\mathrm{Q}_{\mathrm{w}}$ were recorded for the $\mathrm{B}$ insert. For $\mathrm{Q}_{\mathrm{wmax}}=56 \mathrm{~m}^{3} / \mathrm{h}$ pressure drop of insert $\mathrm{B}$ has value $\Delta \mathrm{p}_{\mathrm{w}}=439.9 \mathrm{~Pa}$ (Fig. 12). Filter materials $\mathrm{B}$ and $\mathrm{C}$ achieve slightly lower pressure drop. Filter element made of material $\mathrm{A}$, which is only a cellulose filter material, achieves the lowest pressure drop $\left(\Delta \mathrm{p}_{\mathrm{w}}=312 \mathrm{~Pa}\right)$ which results from material high permeability $\left(838 \mathrm{dm}^{3} / \mathrm{m}^{2} / \mathrm{s}\right)$.

Separation efficiency $\varphi_{\mathrm{w}}$ and pressure drop $\Delta \mathrm{p}_{\mathrm{w}}$ characteristics depending on dust absorption coefficient $\mathrm{k}_{\mathrm{m}}$ of tested filter inserts A, B, C and D are shown on Fig. 13. Observing change in separation efficiency $\varphi_{\mathrm{w}}$ in tested filter inserts, the work of the element can be conventionally divided into two stages. It was assumed that the first (I), initial operation stage of each filter cartridges, lasts until they achieve separation efficiency at the level of $\varphi_{\mathrm{w}}=99.9 \%$. This stage is characterized by a low initial efficiency and separation accuracy and low flow resistance.

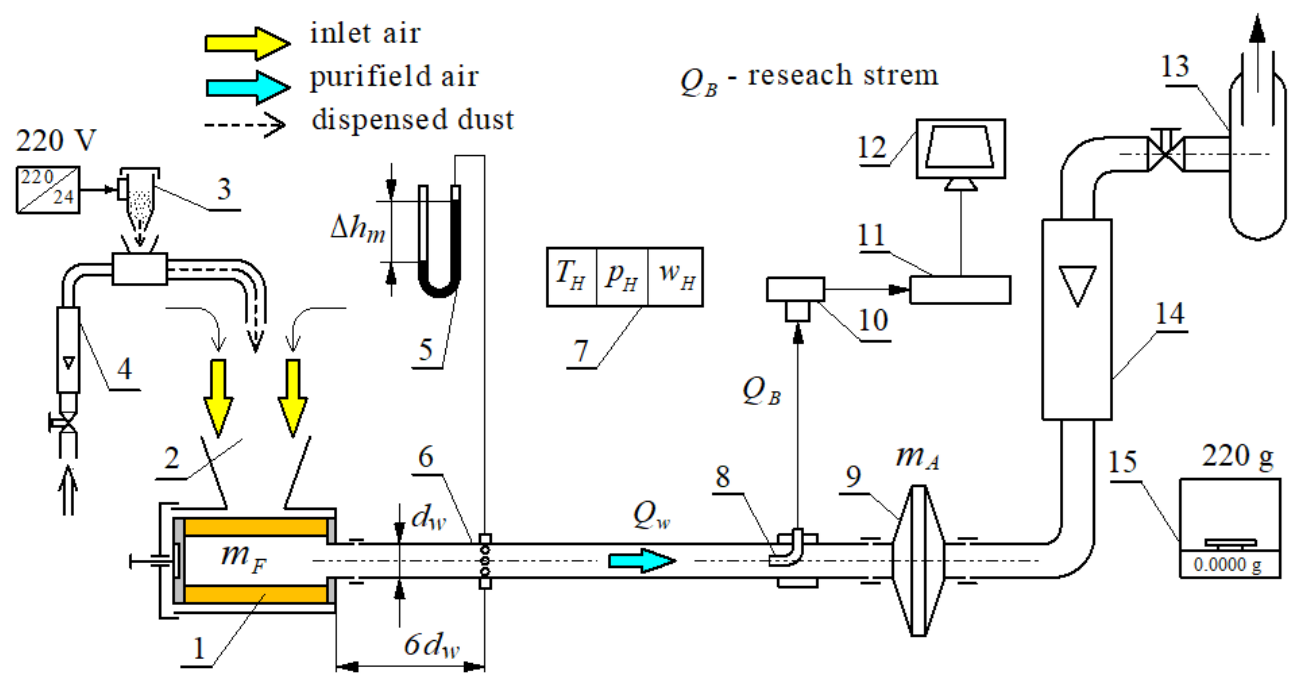

Fig. 11. Filter cartridge test stand functional diagram: 1 - filter cartridge, 2 - dust chamber, 3 - dust dispenser, 4 - rotameter, 5 - U-type manometer tube, 6 - measuring tube, 7 - humidity measurement set, ambient air temperature and pressure, 8 - measuring probe, 9 - absolute filter, 10 - sensor, 11 - particle counter, 12 - measuring computer, 13 - suction fan, 14 - rotameter, 15 - analytical balance 
First (I) stage duration of operation varies and depends on filter material type. Step (I) takes longer the lower the initial separation efficiency is. Lowest initial separation efficiency $\left(\varphi_{\mathrm{w} 0 \mathrm{~A}}=96.3 \%\right)$ was recorded for filter cartridge made of A filter material (cellulose). The B, C and D cartridges have higher separation efficiency initial values, respectively: $\varphi_{\mathrm{w} 0 \mathrm{~B}}=98.9 \%, \varphi_{\mathrm{w} 0 \mathrm{C}}=98.2 \%, \varphi_{\mathrm{w} 0 \mathrm{D}}=99.8 \%$ (Fig. 13).

As dust mass retained in filtration layer increases $\left(\mathrm{k}_{\mathrm{m}}\right.$ coefficient increases) separation efficiency in tested inserts assumes higher and higher values. Determined separation efficiency value $\left(\varphi_{\mathrm{w}}=99.9 \%\right.$ - end of period I) filter cartridges operating under same conditions (same dust concentration and air stream value) obtain after different time. Insert $A$ achieves efficiency of $\varphi_{\mathrm{w}}=99.9 \%$ after obtaining dust absorption coefficient $\mathrm{k}_{\mathrm{mA}}=110.7 \mathrm{~g} / \mathrm{m}^{2}$. For B, C and $\mathrm{D}$ cartridges made of other filter materials, the first stage lasts much shorter. Insert D, whose filter material is a bed (cellulose + polyester + nanofibers $)$, achieves efficiency of $\varphi_{\mathrm{w}}=99.9 \%$ with dust absorption coefficient value $\mathrm{k}_{\mathrm{mD}}=7.22 \mathrm{~g} / \mathrm{m}^{2}$.

In the second (II) stage of work, filter cartridges separation efficiency is maintained at a stabilized level $\varphi_{\mathrm{w}}=99.9 \%$. For the A cartridge, at the end of its work, a slight but systematic decrease in separation efficiency is noticeable. In the last measurement, the effectiveness is $\varphi_{\mathrm{w}}=99.7 \%$. This can be explained by the fact that a considerable dust mass in the form of expanded tree-like dendrites is accumulated on filter material fibers [57]. Dust grains at the very top of the dendrites are entrained and carried to filter material outlet side, from where they are entrained by the air stream flowing into the engine cylinders. Separation efficiency decrease phenomenon is related to dust particles maximum size, which assume larger values. After last measurement, value is $d_{\text {zmaxA }}=16.7 \mu \mathrm{m}$. For the remaining cartridges, maximum dust grain sizes $d_{z \max }$ stabilize at much lower level. Behind insert D, where there is nanofiber layer, these are grains with sizes $d_{\mathrm{zmaxD}}=3.1$ $5.1 \mu \mathrm{m}$.
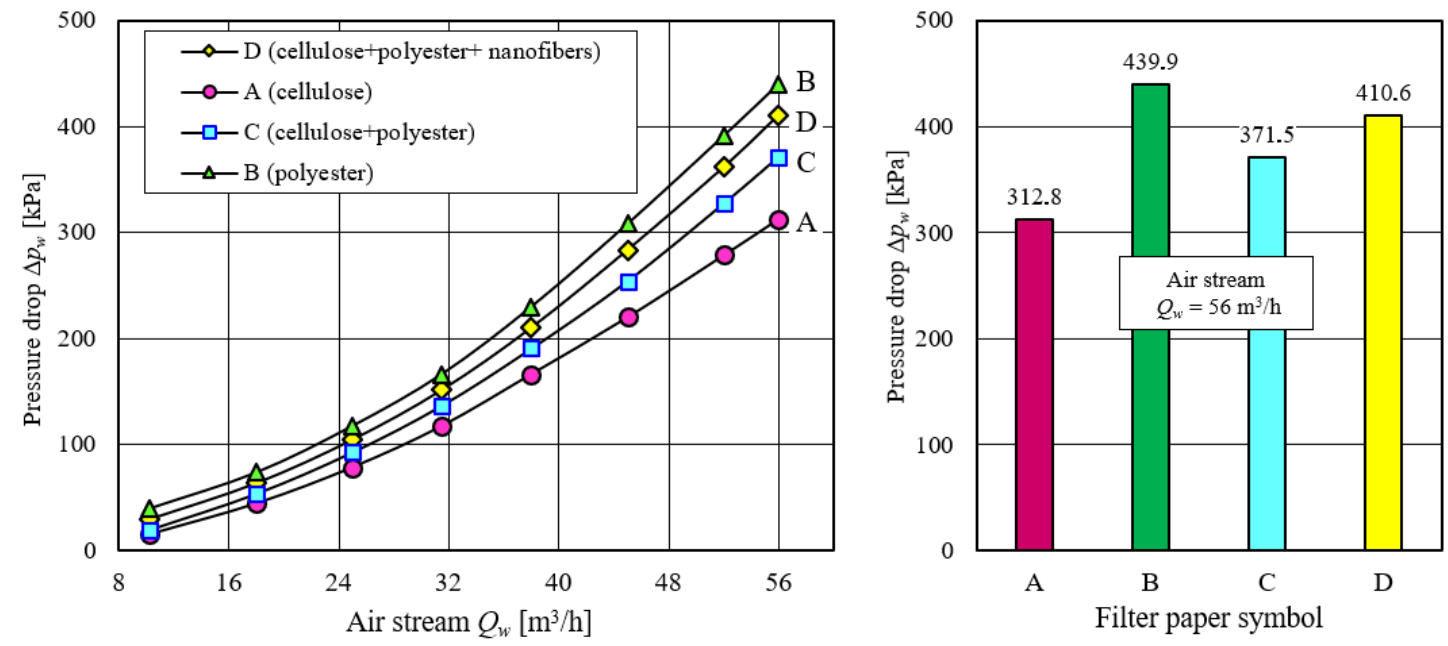

Fig. 12. Flow characteristics $\Delta \mathrm{p}_{\mathrm{w}}=\mathrm{f}\left(\mathrm{Q}_{\mathrm{w}}\right)$ of tested filter cartridges $\mathrm{A}, \mathrm{B}, \mathrm{C}, \mathrm{D}$

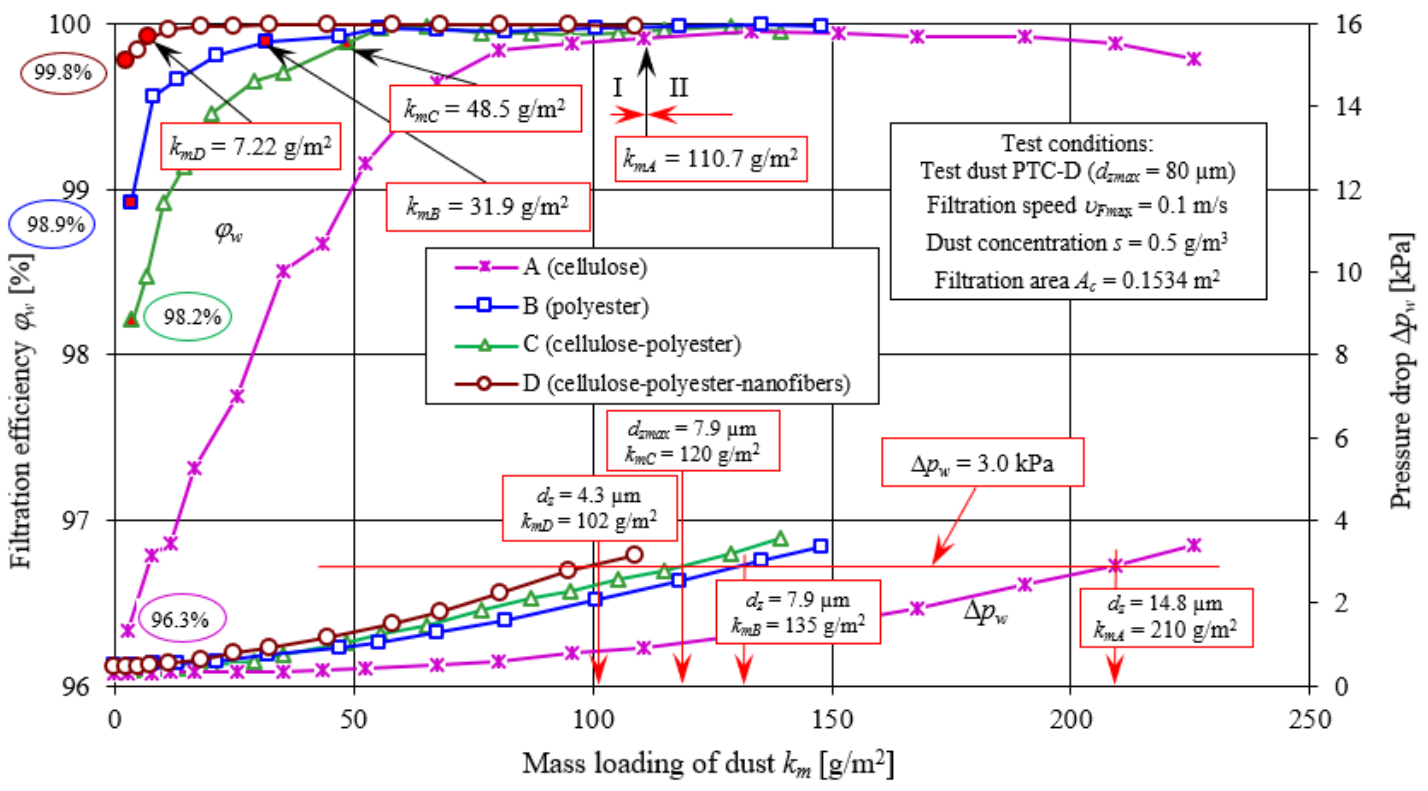

Fig. 13. Performance $\varphi_{\mathrm{w}}$ and pressure drop $\Delta \mathrm{p}_{\mathrm{w}}$ characteristics depending on dust absorption coefficient $\mathrm{k}_{\mathrm{m}}$ of tested filter cartridges A, B, C, D 
Dust retention characteristic feature by filter materials is continuous increase in pressure drop. Due to its negative impact on the engine operation, its limitation in the form of permissible resistance is applied. For passenger car engines, the value is $3 \mathrm{kPa}$. Figure 13 shows that for this permissible resistance value, dust absorption coefficient $\mathrm{k}_{\mathrm{m}}$ in tested filter materials assumes various values. The lowest value was obtained for the cartridge $\mathrm{D}-\mathrm{k}_{\mathrm{mD}}=102 \mathrm{~g} / \mathrm{m}^{2}$, and the highest for cartridge $\mathrm{k}_{\mathrm{mA}}=210 \mathrm{~g} / \mathrm{m}^{2}$, which is related to different material separation properties.

\section{Forecasting vehicle mileage}

Forecasting the distance traveled by the car depending on one of the parameters appearing in eq. (7) is possible while establishing the remaining parameters at a constant level. The equation (7) shows that the parameters that determine the value of the distance travelled are: filter surface $\mathrm{A}_{\mathrm{c}}$ of the cartridge and dust concentration $\mathrm{s}$ in the air sucked in by the filter, which is a variable value, the filter paper absorption coefficient $\mathrm{k}_{\mathrm{m}}$, which depends on the type of paper used. Separation efficiency of modern filter papers can be assumed constant at the minimum level of $99.5 \%$. As a rule, the nominal air demand of the engine is taken as the maximum $\mathrm{Q}_{\text {Silmax }}$.

Figure 14 shows an example of mileage changes calculation until the permissible resistance depending on the dust concentration in the air of two passenger cars Audi 80 B2 1.6 GLE and VW Golf II with naturally aspirated engines of the cubic capacity $\mathrm{V}_{\mathrm{ss}}=1.558 \mathrm{dm}^{3}$ but with different power and area filter paper surface. The analysis was performed in the range of air dust concentration $\mathrm{s}=0.0004$ $0.1 \mathrm{~g} / \mathrm{m}^{3}$, which may occur on motorways [2] and assuming the filter paper absorption coefficient $\mathrm{k}_{\mathrm{m}}=220 \mathrm{~g} / \mathrm{m}^{2}$.

As dust concentration in the air increases, the car mileage until reaching the permissible resistance decreases, while the car mileage with an Audi engine are five times shorter, which is because of the active surface of the $A_{c}$ filter paper (by over 50\%) smaller than that of the VW car filter and thus dust absorption. The smaller surface of the filter paper means not only high separation speed and increased pressure drop, but also shorter car mileage with an efficient air filter. Audi engine air filter with the surface of the filter paper $A_{c}=0.708 \mathrm{~m}^{2}$ and absorbency $\mathrm{k}_{\mathrm{m}}=220$ $\mathrm{g} / \mathrm{m}^{2}$ is able to retain dust until the permissible resistance of $156 \mathrm{~g}$. A VW car engine air filter with a filter paper area of $\mathrm{A}_{\mathrm{c}}=1.63 \mathrm{~m}^{2}$ will retain $359 \mathrm{~g}$ of dust.

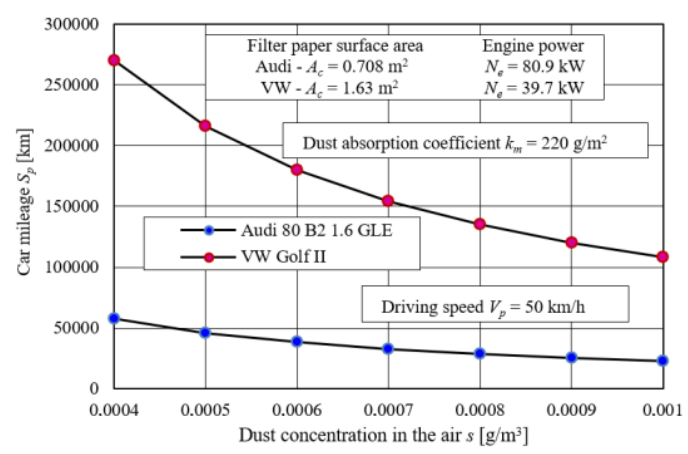

Fig. 14. Vehicle mileage until the filter reaches the permissible resistance depending on dust concentration in the air and different filter paper surfaces from two different filters
After the filter insert reaches permissible resistance, the cartridge should be replaced with a new one. In passenger cars, this operation is performed after a specified mileage set by the car manufacturer (Table 2).

When selecting the filter material for the air filter, its absorbency is also important. Fig. 11 shows an example of mileage calculation changes until the permissible resistance depending on dust concentration in the air is reached for passenger cars Audi 80 B2 1.6 GLE VW Golf II with different values of the filter material absorption coefficient, respectively: $\mathrm{k}_{\mathrm{m} 1}=220 \mathrm{~g} / \mathrm{m}^{2}, \mathrm{k}_{\mathrm{m} 2}=135 \mathrm{~g} / \mathrm{m}^{2}, \mathrm{k}_{\mathrm{m} 3}=102$ $\mathrm{g} / \mathrm{m}^{2}$.

Table 2. Car mileage to replace the filter insert

\begin{tabular}{|l|c|c|c|}
\hline No. & Car & $\begin{array}{c}\text { Type of } \\
\text { filter insert }\end{array}$ & $\begin{array}{c}\text { Car mileage to replace } \\
\text { the filter insert } S_{\mathrm{w}}[\mathrm{km}]\end{array}$ \\
\hline 1 & Skoda Octavia 1.6 & panel & 60000 \\
\hline 2 & Honda Civic & panel & 40000 \\
\hline 3 & Ford Fiesta & panel & 40000 \\
\hline 4 & Citroen ZX & panel & 30000 \\
\hline 5 & Land Rover Defender & panel & 20000 \\
\hline 6 & Opel Corsa & panel & 10000 \\
\hline
\end{tabular}

Graphs in Fig. 15 show that the use of filter materials with lower absorbency shortens the distance traveled by the car until permissible resistance by the filter is reached, and thus the insert is replaced with a new one. In the case of air filters having a smaller surface of the filter paper than that resulting from the correct selection, this phenomenon increases.

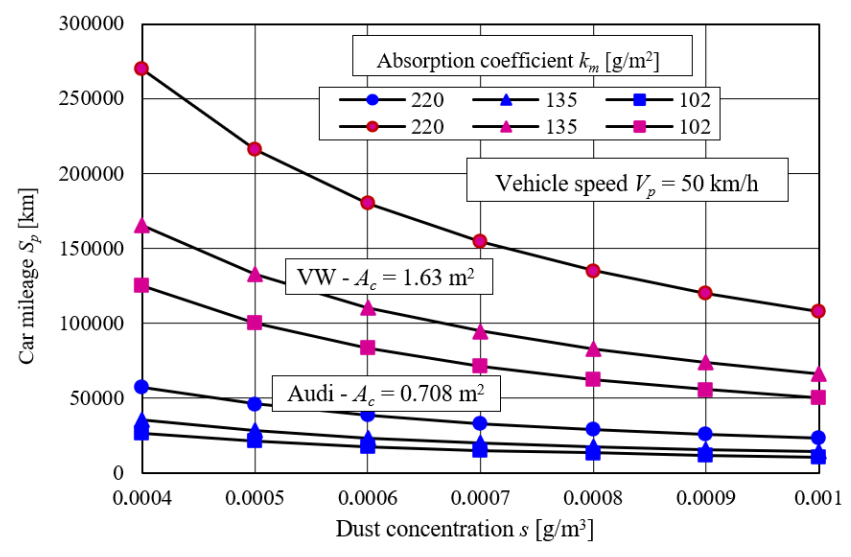

Fig. 15. Vehicle mileage until the filter reaches the permissible resistance depending on air dust concentration and various dust absorption coefficients of the filter material

\section{Summary}

The aim of this thesis was to experimentally verify the basic criterion (permissible separation speed $v_{F \max }$ ) for the separation surface selection of a pleated insert for a passenger car engine air filter. Geometry of 44 pleated filter inserts used in passenger car engine air filters, differing in cubic capacity, power, and degree of filling, was analyzed, and then the actual filter paper area of each air filter was determined. Using the theoretical dependence, the nominal air stream flowing through the filter was calculated, and then the separation speed for the analyzed filter inserts was calculated, which was compared with the permissible value 
of $v_{\text {Fmax }}$ applicable in the automotive industry. In the second stage, the influence of paper surface and other factors determining the value of the distance traveled by a passenger car until the filter obtained a permissible pressure drop was analyzed. For this purpose, the theoretical dependence was used, which takes into account many experimentally determined factors, which makes the forecast more reliable. The theoretical and experimental analysis shows that:

1. in most cases, the actual (active) inserts filtering surface $A_{R}$ is greater than the calculated surface $A_{N}$ from the condition of the permissible separation velocity $v_{\mathrm{Fmax}}=$ $0.12 \mathrm{~m} / \mathrm{s}$. This indicates the correct selection of filter surface and air filters for the vehicle.

2. In most cases $(62 \%)$ of analyzed filter inserts, calculated separation speeds are within the permissible speed range recommended by the designers $v_{\text {Fmax }}=0.06-0.12 \mathrm{~m} / \mathrm{s}$.

3. Exceeding the maximum permissible separation speed $v_{\text {Fmax }}=0.12 \mathrm{~m} / \mathrm{s}$ was seen mainly in filter elements of supercharged and high-power engines. It follows that an important factor determining the surface of the filter paper, and then separation speed, is the free space around the engine where it is possible to place the air filter with filter paper of required surface. The analysis shows that this free space is missing in cars where high-power engines are installed.

4. Active insert filtering surface $A_{c}$ determines not only the separation speed, but also the value of the distance travelled until the permissible filter resistance is reached, and thus the replacement of the filter cartridge.

5. When selecting a filter material for a car engine air filter, it should be known that modern filter materials used in the production of engine filter elements are more efficient and accurate than conventional cellulosebased materials, but dust absorption is lower by half. It has very big importance when forecasting vehicle mileage, because for the same paper surface, the absorptive capacity of the insert and the vehicle mileage are proportionally lower.

It is possible to run the engine with an air filter with a smaller filter material surface area. Separation process then takes place at a higher speed, which causes a decrease in separation efficiency and increased pressure drop. Along with dust accumulation in filter bed, the process of pressure drop increases. This has negative effects in the form of engine energy losses. A much higher than the permissible flow resistance may cause paper insert destruction, and then contaminants flow into the engine cylinders, causing accelerated abrasive wear of the mating surfaces, clearances enlargement, decreased tightness of the "piston-cylinder" connection and a decrease in engine power.

\section{Acknowledgements}

This work was financed by Military University of Technology under research project UGB 881/2021.

\section{Nomenclature}

$\mathrm{A}_{\mathrm{c}} \quad$ cartridge active filtering area

CFD computational fluid dynamics

$\mathrm{d}_{\mathrm{zmax}}$ maximum dust grains size after the filter

EGR Exhaust Gas Recirculation

$\mathrm{k}_{\mathrm{m}} \quad$ filter paper absorbency coefficient

$\mathrm{P}-\mathrm{P}-\mathrm{C}$ piston-piston rings-cylinder walls

q air filter quality factor

$\mathrm{Q}_{\text {Silmax }}$ maximum air requirement for the engine
$\mathrm{Q}_{\mathrm{w}} \quad$ air stream flowing through the filter element

SI spark ignition

TDI Turbo Direct Injection

$\Delta \mathrm{p}_{\text {fdop }}$ air filter permissible resistance

$\varphi_{\mathrm{w}} \quad$ cartridge separation efficiency

$v_{\text {Fmax }}$ maximum separation speed

$\mathrm{U}_{\mathrm{FR}} \quad$ actual separation speed

\section{Bibliography}

[1] ALLAM, S., ELSAID, A.M. Parametric study on vehicle fuel economy and optimization criteria of the pleated air filter designs to improve the performance of an I.C diesel engine: experimental and CFD approaches. Separation and Purification Technology. 2020, 241, 116680. https://doi.org/10.1016/j.seppur.2020.116680

[2] BARBOLINI, M., DI PAULI, F., TRAINA, M. Simulation der Luftfiltration zur Auslegung von Filterelementen. MTZMotortechnische Zeitschrift. 2014, 75(11), 52-57.

[3] BARRIS, M.A. Total Filtration ${ }^{\mathrm{TM}}$. The influence of filter selection on engine wear. Emissions and performance. SAE Technical Paper 952557. 1995. https://doi.org/10.4271/952557

[4] BOJDO, N., FILIPPONE, A. Effect of desert particulate composition on helicopter engine degradation rate. $40^{\text {th }} \mathrm{Eu}$ ropean Rotorcraft Forum. Southampton. 2014. https://doi.org/10.13140/2.1.2959.8086

[5] BRAUN, R., SAUTER, H., SEGGERN, J. et al. Motorluftfiltration. MTZ-Motortechnische Zeitschrift. 2006, 67(12), 974-980. https://doi.org/10.1007/bf03225436
[6] BUGLI, N.J., GREEN, G.S. Performance and benefits of zero maintenance air induction systems. SAE Technical Paper 200501-1139. 2005. https://doi.org/10.4271/2005-01-1139

[7] CHEN, D.R., PUI, D.Y.H., LIU, B.Y.H. Optimization of pleated filter designs using a finite-element numerical model. Aerosol Science and Technology. 1995, 23(4), 579-590. https://doi.org/10.1080/02786829508965339

[8] CHEN, C.W., HUANG, S.H., CHIANG, C.M. et al. Filter quality of pleated filter cartridges. Annals of Occupational Hygiene. 2008, 52(3), 207-212.

https://doi.org/10.1093/annhyg/men008

[9] DAHLAN, A.A., MUHAMMAD SAID M.F., ABDUL LATIFF, Z. et al. Acoustic study of an air intake system of SI engine using 1-dimensional approach. International Journal of Automotive and Mechanical Engineering (IJAME). 2019, 16(1), 6281-6300.

https://doi.org/10.15282/ijame.16.1.2019.14.0476

[10] DEL FABBRO, L., LABORDE, J.C., MERLIN, P. et al. Air flows and pressure drop modelling for different pleated industrial filters. Filtration \& Separation. 2002, 39(1), 35-40. https://doi.org/10.1016/S0015-1882(02)80055-6 
[11] DURST, M., KLEIN, G., MOSER, N. Filtration in Fahrzeugen. Mann+Hummel GMBH. Ludwigsburg 2005.

[12] DZIUBAK, T., DZIUBAK, S.D. Experimental study of filtration materials used in the car air intake. Materials. 2020, 13(16), 3498. https://doi.org/10.3390/ma13163498

[13] DZIUBAK, T., BĄKAŁA, L. Experimental research of the material filtration characteristics with nanofibers addition. Journal of KONES Powertrain and Transport. 2018, 25(4), 83-94. https://doi.org/10.5604/01.3001.0012.4779

[14] DZIUBAK, T., SZWEDKOWICZ, S. Operating properties of non-woven fabric panel filters for internal combustion engine inlet air in single and two-stage filtration systems. Eksploatacja i Niezawodność - Maintenance and Reliability. 2015, 17(4), 519-527.

https://doi.org/10.17531/ein.2015.4.6

[15] Engine air cleaners, service parts and accessories. https://www.donaldson.com/content/dam/donaldson/enginehydraulics-bulk/catalogs/air-intake/emea/f116005/AirIntake-Product-Guide.pdf

[16] ERDMANNSDÖRFER, H. Lesttingmoglichkeiten von Papierfiltern zur Reinigung der Ansaugluft von Diselmotoren. MTZ-Motortechnische Zeitschrift. 1971, 32, 123-131.

[17] FENG, Z., LONG, Z. Modeling unsteady filtration performance of pleated filter. Aerosol Science and Technology. 2016, 50(6), 626-637.

https://doi.org/10.1080/02786826.2016.1172058

[18] FLECK, S., HEIM, M., BECK, A. et al. Realitätsnahe Prüfung von Motoransaugluftfiltern, MTZ-Motortechnische Zeitschrift. 2009, 70, 414-418. https://doi.org/10.1007/BF03225494

[19] FOTOVATI, S., HOSSEINI, S., TAFRESHI, H. et al. Modeling instantaneous pressure drop of pleated thin filter media during dust loading, Chemical Engineering Science. 2011, 66(18), 4036-4046. https://doi.org/10.1016/j.ces.2011.05.038

[20] FOTOVATI, S., TAFRESHI, H.V., POURDEYHIMI, B. A macroscopic model for simulating pressure drop and collection efficiency of pleated filters over time. Separation and Purification Technology. 2012, 98, 344-355. https://doi.org/10.1016/j.seppur.2012.07.009

[21] GERVAIS, P.C., POUSSIER, S., BARDIN-MONNIER, N. et al. Combination of single-photon emission and X-Ray computed tomography to visualize aerosol deposition in pleated filter. Separation and Purification Technology. 2014, 126, 52-61. https://doi.org/10.1016/j.seppur.2014.02.011

[22] HALIM, M.A.A., MOHD, N.A.R., NASIR, M.N.M. et al. Experimental and numerical analysis of a motorcycle air intake system aerodynamics and performance. International Journal of Automotive and Mechanical Engineering (IJAME). 2020, 17(1), 7607-7617.

https://doi.org/10.15282/ijame

[23] JAROSZCZYK, T., FALLON, S.L., LIU, Z.G. et al. Development of a method to measure engine air cleaner fractional efficiency. SAE Technical Paper 1999-01-0002. 1999. https://doi.org/10.4271/1999-01-0002

[24] JIN-RUI, X., FU-PING, Q., JIN-LI, L. et al. Threedimensional microstructure reconstruction of pleated air filter media and simulation of its performance in dust filtration stage. Chinese Journal of Process Engineering. 2017, 17(1) 170-177. https://doi.org/10.12034/j.issn.1009-606X.216190

[25] KAHRSTEDT, J., ZÜLCH, S., STRENG, CH. et al. Neue Generation des 3.0-L-Tdi-Motors von Audi. MTZMotortechnische Zeitschrift. 2010, 11(71), 800-807. https://doi.org/10.1007/BF03225625

[26] KANG, S., BOCK, N., SWANSON, J. et al. Characterization of pleated filter media using particle image velocimetry.
Separation and Purification Technology. 2020, 237, 116333. 116333. https://doi.org/10.1016/j.seppur.2019.116333

[27] LI, S., HU, S., XIE, B. et al. Influence of pleat geometry on the filtration and cleaning characteristics of filter media. Separation and Purification Technology. 2019, 210, 38-47. https://doi.org/10.1016/j.seppur.2018.05.002

[28] LONG, J., TANG, M., SUN, Z. et al. Dust loading performance of a novel submicro-fiber composite filter medium for engine. Materials. 2018, 11, 2038. https://doi.org/10.3390/ma11102038.

[29] MAHESH, J. Parametric study and CFD analysis of air filter. Asian Journal of Convergence in Technology (AJCT). 2019, 5(1), 1-9. www.asianssr.org

[30] MADDINENI, A.K., DAS, D, DAMODARAN, R.M. Experimental and numerical study on automotive pleated air filters. SAE Technical Paper 2016-28-0100. 2016. https://doi.org/10.4271/2016-28-0100

[31] MADDINENI, A.K., DAS, D., DAMODARAN, R.M. Airborne particle by fibrous filter media under collision effect: a CFD-based approach. Separation and Purification Technology. 2018, 193, 1-10.

https://doi.org/10.1016/j.seppur.2017.10.065

[32] MADDINENI, A.K., DAS, D., DAMODARAN, R.M. Numerical investigation of pressure and flow characteristics of pleated air filter system for automotive engine intake application. Separation and Purification Technology. 2019, 212, 126-134. https://doi.org/10.1016/j.seppur.2018.11.014

[33] MADDINENI, A.K., DAS, D., DAMODARAN, R.M. Oiltreated pleated fibrous air filters for motor vehicle engine intake application. Proceedings of the Institution of Mechanical Engineers, Part D: Journal of Automobile Engineering, 2019, 234(2-3), 702-713.

https://doi.org/10.1177/0954407019850379

[34] MELZER, H.H., BROX, W. Ansauggerauschdampfer und Luftfilter für BMW 524 td, MTZ-Motortechnische Zeitschrift. 1984, 45, 223-227.

[35] KWON, M-S., KIM Y-L., KIM, M-S. et al. Effect of pleating ratio on quality factor of pleated filter in air purifier. Journal of Korean Society for Atmospheric Environment. 2020, 36(1), 119-127. https://doi.org/10.5572/KOSAE.2020.36.1.119

[36] MUSTAFA, N.S., NGADIMAN, N.H.A., ABAS, M.A. et al. Application of box-behnken analysis on the optimisation of air intake system for a naturally aspirated engine. International Journal of Automotive and Mechanical Engineering (IJAME). 2020, 17(2), 7607-7617.

https://doi.org/10.15282/ijame.17.2.2020.21.0602

[37] NORMAN, K., HUFF, S., WEST, B. Effect of intake air filter condition on vehicle fuel economy. U.S. Department of Energy (DOE) Information Bridge. 2009. http://www.osti.gov/bridge

[38] PARK, B., LEE, M., JO, Y. et al. Influence of pleat geometry on filter cleaning in a PTFE/glass composite filter. Journal of the Air \& Waste Management Association. 2012, 62, 1257-1263. https://doi.org/10.1080/10962247.2012.696530

[39] PN-S-34040, Filtry powietrza. Wymagania i badania, PKN 1996.

[40] REBAI, M., PRAT, M., MEIRELES, M. et al. A semianalytical model for gas flow in pleated filters. Chemical Engineering Science. 2010, 65, 2835-2846. https://doi.org/10.1016/j.ces.2010.01.014

[41] REBAI, M., PRAT, M., MEIRELES, M. et al. Clogging modeling in pleated filters for gas filtration. Chemical Engineering Research and Design. 2010, 88, 476-486. https://doi.org/10.1016/j.cherd.2009.08.014

[42] SAKTHIVEL, S., EHZIL ANBAN, J.J., RAMACHANDRAN, T. Development of needle-punched nonwoven fab- 
rics from reclaimed fibers for air filtration applications. Journal of Engineered Fibers and Fabrics. 2014, 9, 149154. https://doi.org/10.1177/155892501400900117

[43] SALEH, A., TAFRESHI, H. A simple semi-numerical model for designing pleated air filters under dust loading. Separation and Purification Technology. 2014, 137, 94-108. https://doi.org/10.1016/j.seppur.2014.09.029

[44] SALEH, A.M., HOSSEINI, S.A., TAFRESHI, H.V. et al. 3-D microscale simulation of dust-loading in thin flat-sheet filters: a comparison with 1-D macroscale simulations. Chemical Engineering Science. 2013, 99, 284-291.

https://doi.org/10.1016/j.ces.2013.06.007

[45] SALEH, A.M., FOTOVATI, S., TAFRESHI, H.V. et al. Modeling service life of pleated filters exposed to polydispersed aerosols. Powder Technology. 2014, 266, 79-89. https://doi.org/10.1016/j.powtec.2014.06.011

[46] SALEH, A.M., TAFRESHI, H.V., POURDEYHIMI, B. Service life of circular pleated filters vs. that of their flat counterpart. Separation and Purification Technology. 2015, 156, 881-888. https://doi.org/10.1016/j.seppur.2015.09.041

[47] SAWANT, P., BARI, S. Effects of variable intake valve timings and valve lift on the performance and fuel efficiency of an internal combustion engine. SAE Technical Paper 2018-01-0376. 2018. https://doi.org/10.4271/2018-01-0376

[48] SMIALEK, J.L., ARCHER, F.A., GARLICK, R.G. Turbine airfoil degradation in the persian gulf war. The Journal of The Minerals, Metals \& Materials Society (TMS). 1994, 46(12), 39-41. https://doi.org/10.1007/BF03222663

[49] SUBRENAT, A., BELletre, J., LE ClOIREC, P. 3-D numerical simulations of flows in a cylindrical pleated filter packed with activated carbon cloth. Chemical Engineering Science. 2003, 58, 4965-4973.

https://doi.org/10.1016/j.ces.2003.07.012

[50] TANG, R-J., HU, B-F., ZHANG, M. et al. Study on separation characteristics of dust and droplet on air intake prefiltration systems of $\mathrm{CV}$ based on CFD simulation and test.

Tadeusz Dziubak, DSc., DEng. - Faculty of Mechanical Engineering, Military University of Technology, Warsaw, Poland.

e-mail: tadeusz.dziubak@wat.edu.pl
International Conference on Artificial Intelligence and Computing Science (ICAICS 2019).

https://doi.org/10.12783/dtcse/ icaic2019/29462

[51] TAUFKIRCH, G., MAYR, G. Papierluftfilter für Motoren in Nutzfahrzeugen. MTZ-Motortechnische Zeitschrift. 1984, 45(3), 95-105.

[52] THÉRON, F., JOUBERT, A., COQ, L. Numerical and experimental investigations of the influence of the pleat geometry on the pressure drop and velocity field of a pleated fibrous filter. Separation and Purification Technology. 2017, 182, 69-77.

https://doi.org/10.1016/j.seppur.2017.02.034

[53] TRONVILLE, P., SALA, R. Minimization of resistance in pleated-media air filter designs: empirical and CFD approaches. HVAC\&R Research. 2003, 9, 95-106. https://doi.org/10.1080/10789669.2003.10391058

[54] WIEGMANN, A., RIEF, S., KEHRWALD, D. Computational study of pressure drop dependence on pleat shape and filter media. Filtech 2007 International Conference for Filtration and Separation Technology 2007, 1, 79-86. http://publica.fraunhofer.de/documents/N-470488.html

[55] WRÓBLEWSKI, P., KOSZAŁKA, G. An experimental study on frictional losses of coated piston rings with symmetric and asymmetric geometry. SAE International Journal of Engines. 2021, 14(6). https://doi.org/10.4271/03-14-06-0051

[56] WRÓBLEWSKI, P. Technology for obtaining asymmetries of stereometric shapes of the sealing rings sliding surfaces for selected anti-wear coatings. SAE Technical Paper 202001-2229. 2020. https://doi.org/10.4271/2020-01-2229

[57] VOGEL, A., DURANT, A.J., CASSIANI, M. et al. Simulation of volcanic ash ingestion into a large aero engine: particle-fan interactions. ASME Journal of Turbomachinery. 2019, 141(1), 011010. https://doi.org/10.1038/srep25620

[58] www.retopfibre.en.alibaba

Leszek Bąkała MEng., Ph.D. student - Faculty of Mechanical Engineering, Military University of Technology, Warsaw, Poland. e-mail: leszekbakala@gmail.com
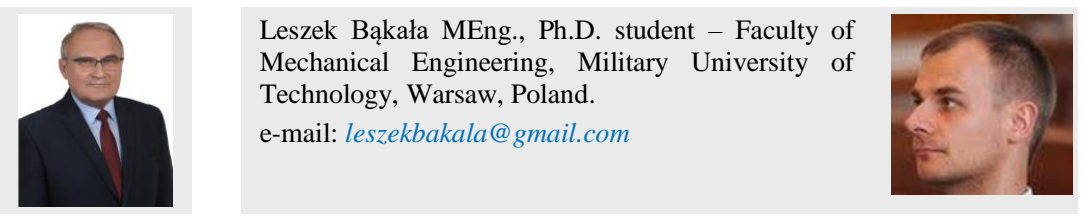